\title{
Elaboration of Functionalized Organophosphates
}

\author{
Kouassi Signo, Zahra Mammasse and Sylvain Canesi*
}

Laboratoire de Méthodologie et Synthèse de Produits Naturels, Université du Québec à Montréal, C.P. 8888, Succ. Centre-Ville, Montréal, H3C 3P8 Québec, Canada.

*E-mail: canesi.sylvain@uqam.ca

\section{Supporting Information}

\author{
Table of Contents
}

1. Copy of ${ }^{1} \mathrm{H}$ NMR spectrum crude for compound 14

2. Copies of ${ }^{1} \mathrm{H}$ and ${ }^{13} \mathrm{C}$ NMR spectra for all compounds and ${ }^{31} \mathrm{P}$ NMR for compounds $16 / 19 / 21 / 22 / 23 / 27$ 


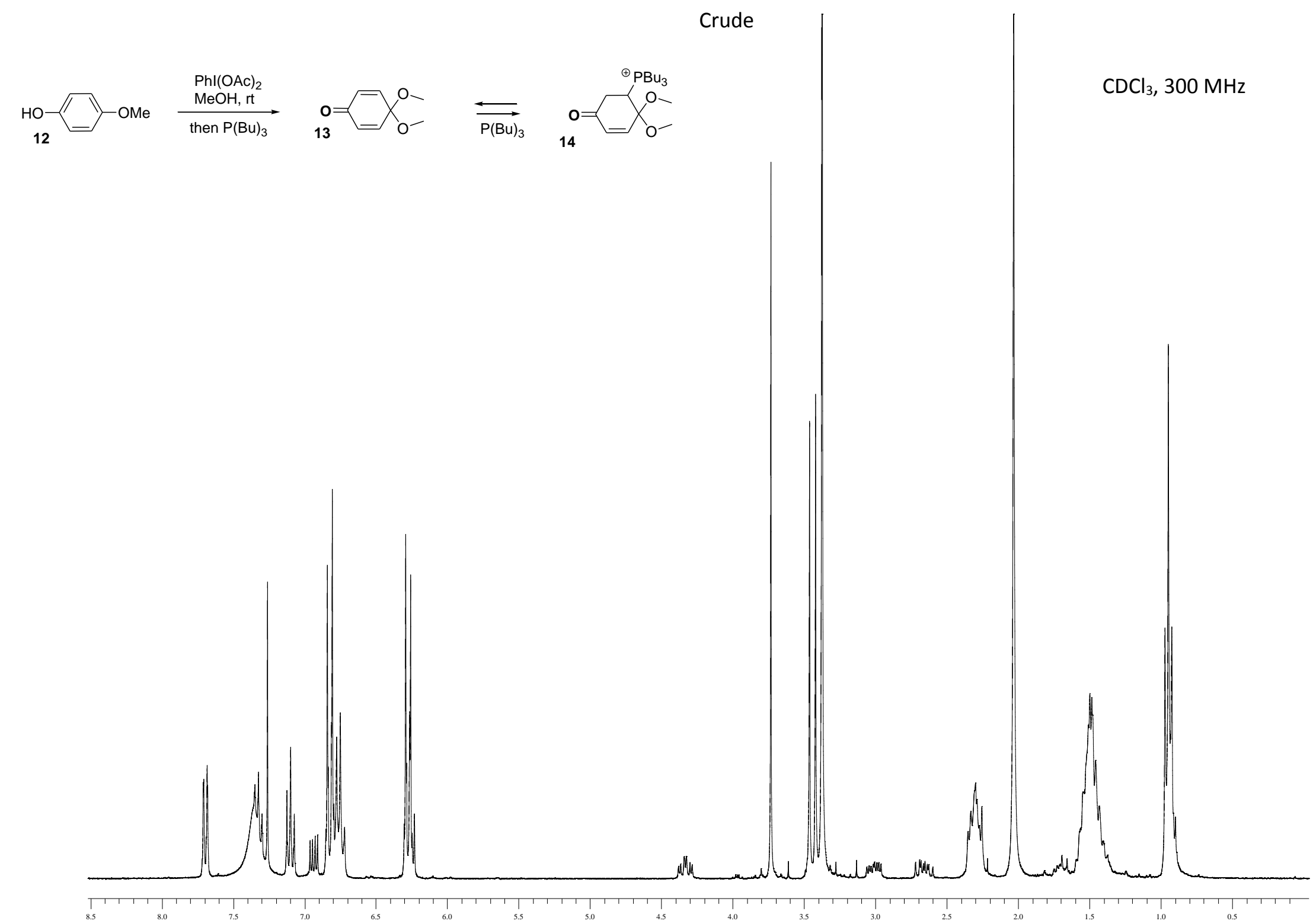




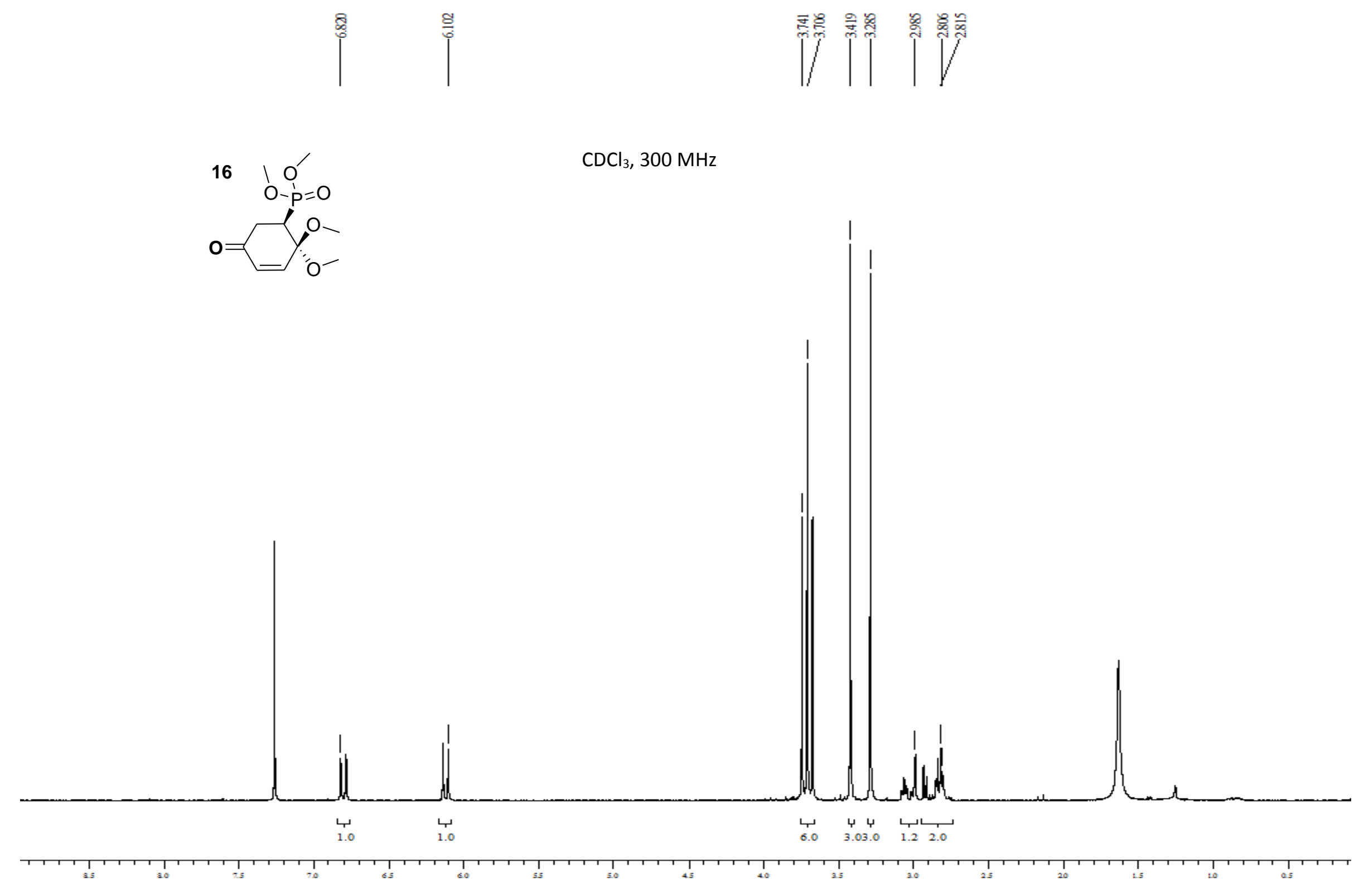



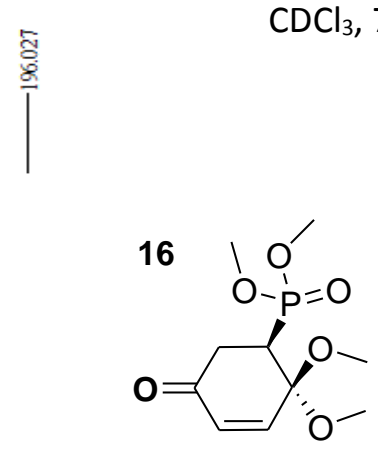
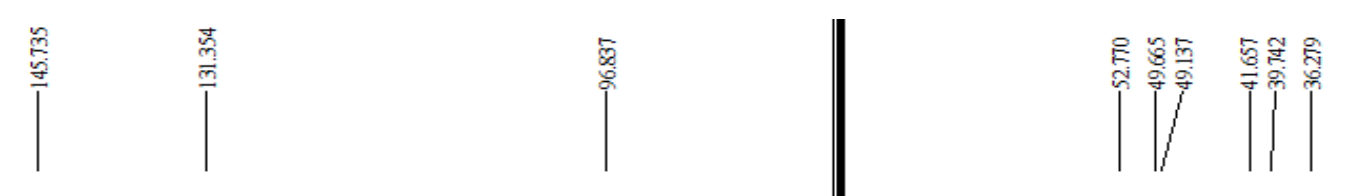

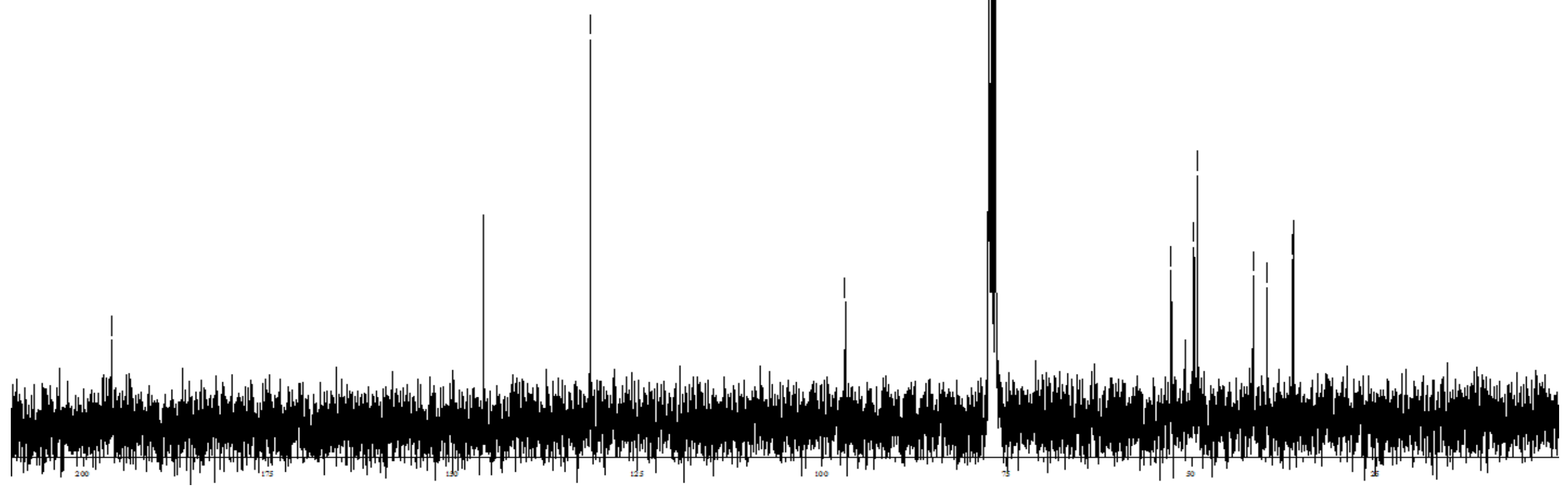

S4 
16

$=\sum^{1}$

淽 $\mathrm{CDCl}_{3}, 122 \mathrm{MHz}$

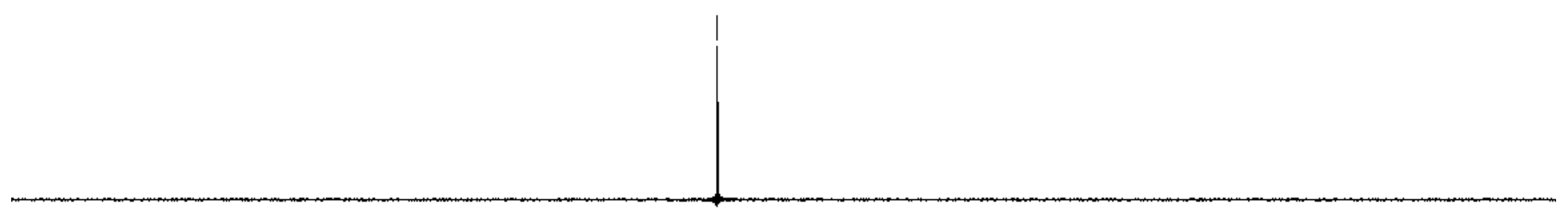





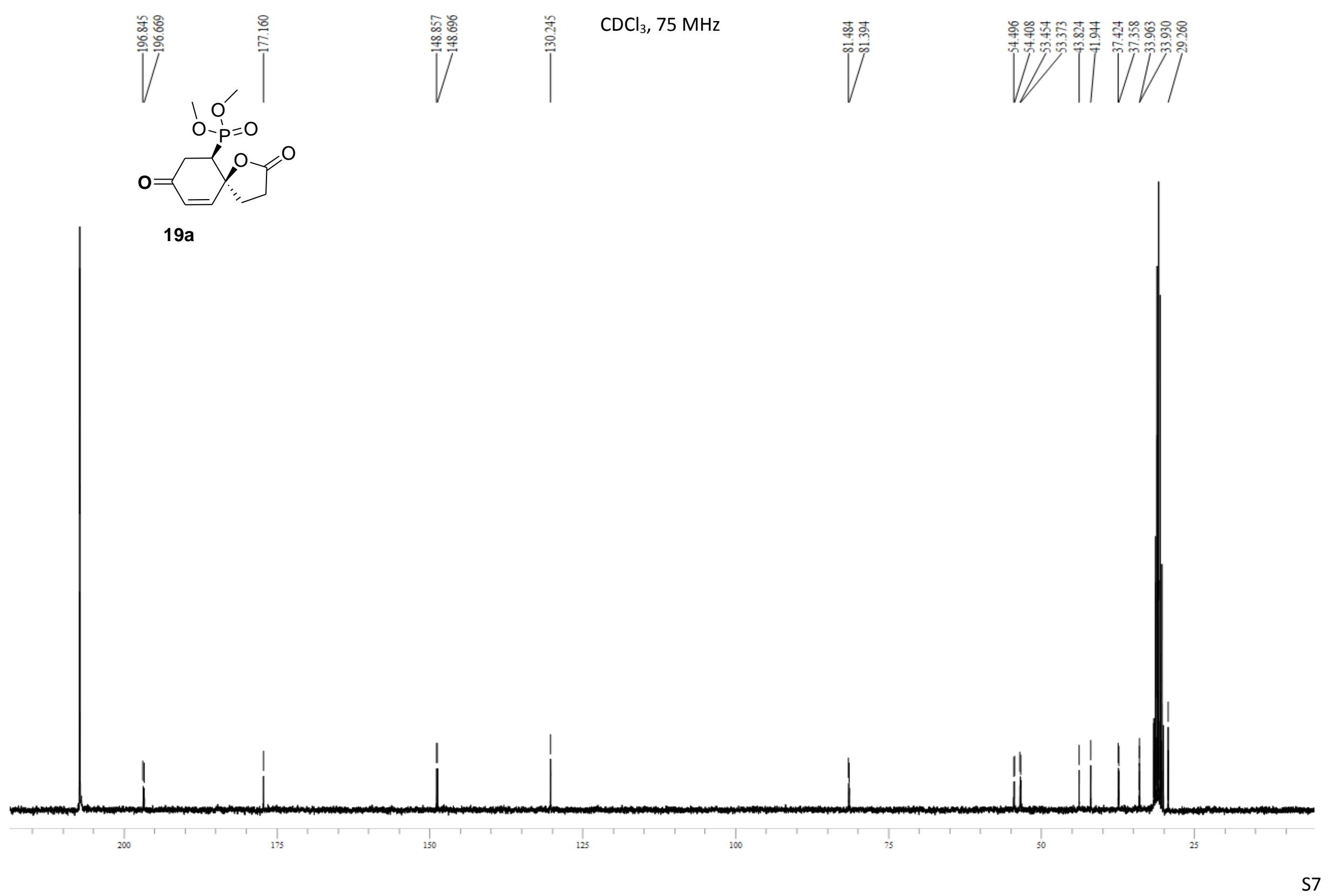




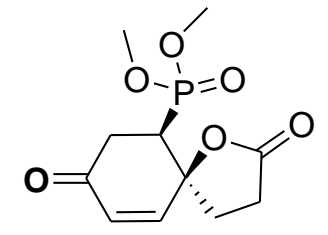

19a
$\mathrm{CDCl}_{3}, 122 \mathrm{MHz}$

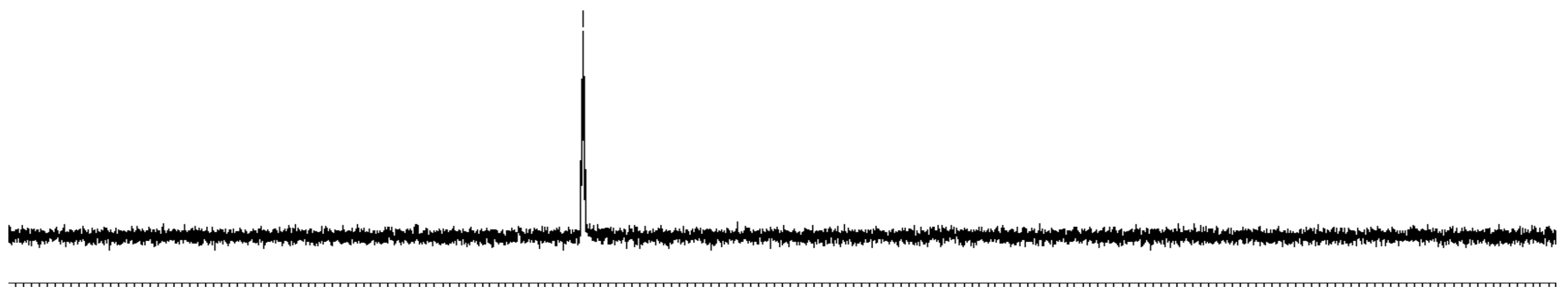




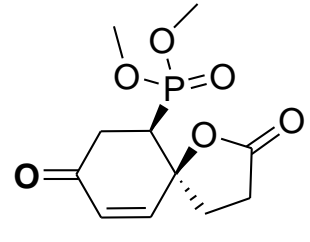

$19 a$
$\mathrm{CDCl}_{3}, 300 \mathrm{MHz}$

\section{NOE, OMe}

irradiation
ผิํํ요

mis

$1 / /$ 


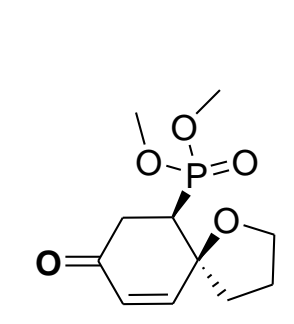

$19 b$
苛

$\mathrm{CDCl}_{3}, 300 \mathrm{MHz}$

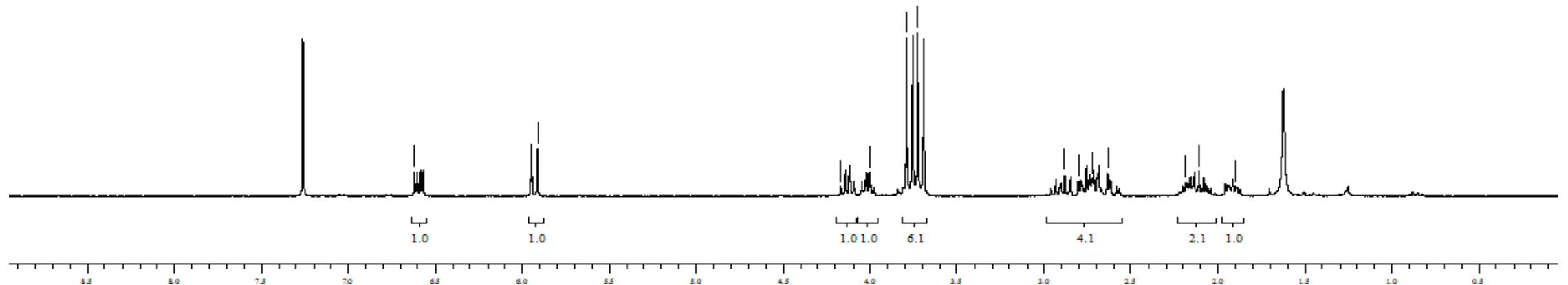



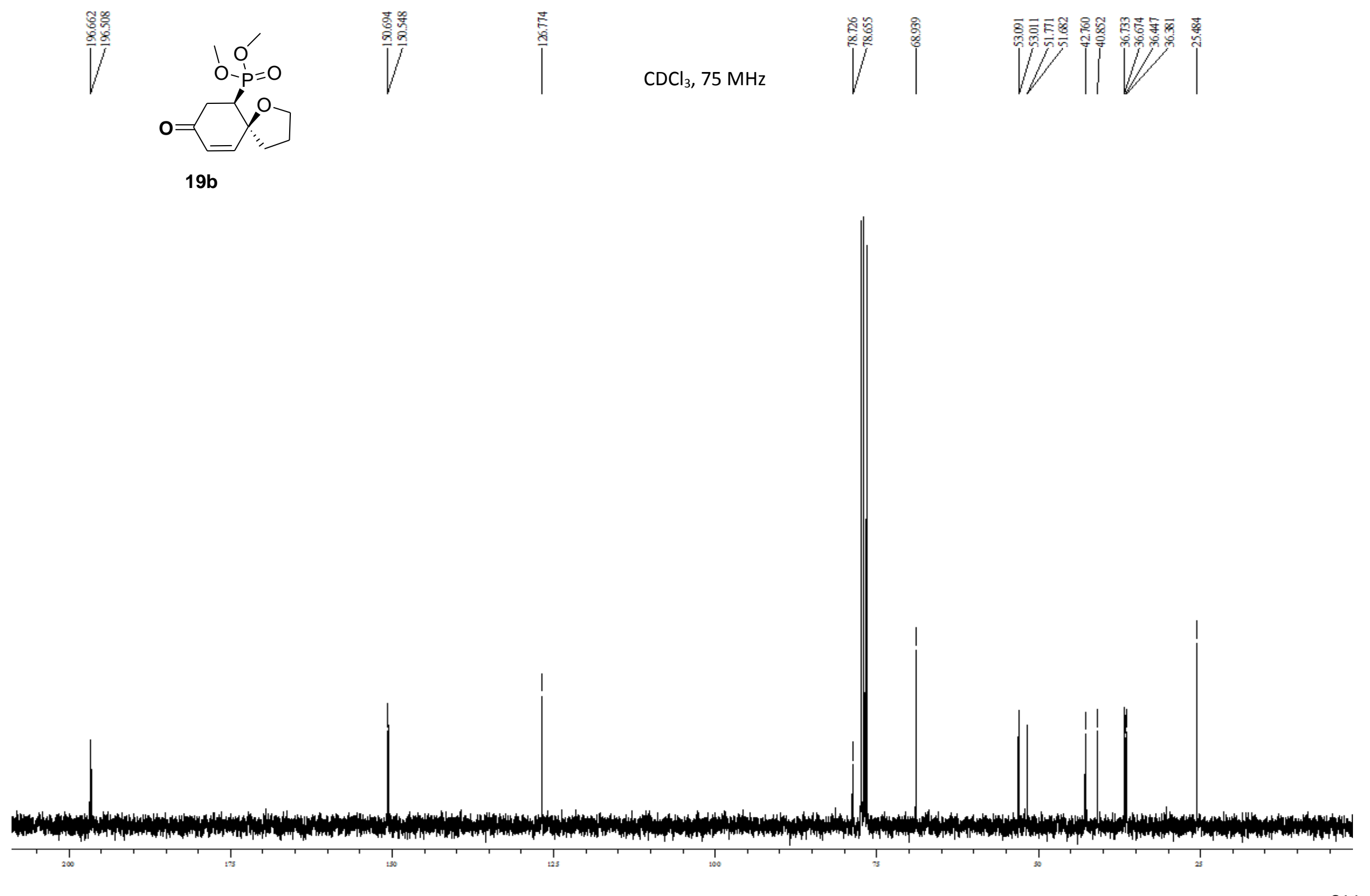


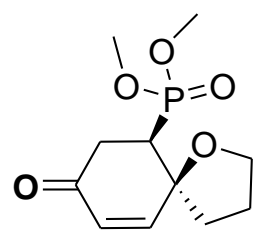

$\mathrm{CDCl}_{3}, 122 \mathrm{MHz}$

$19 b$

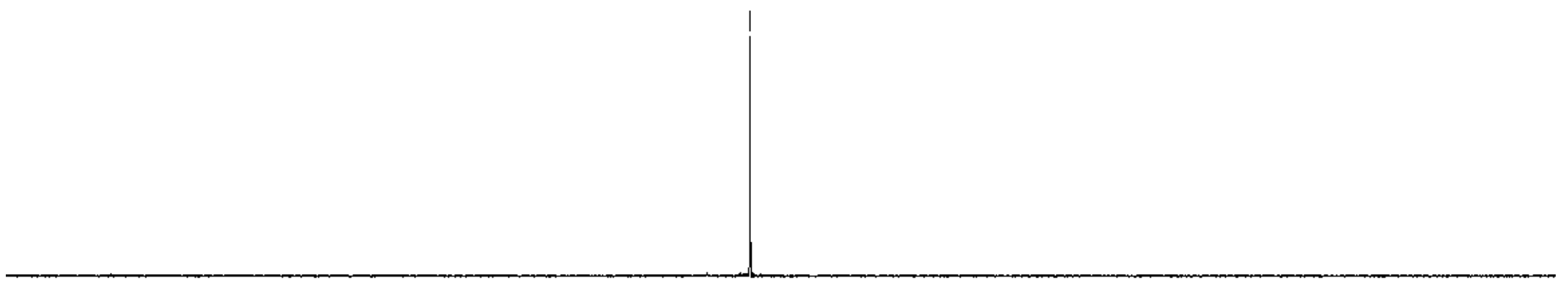



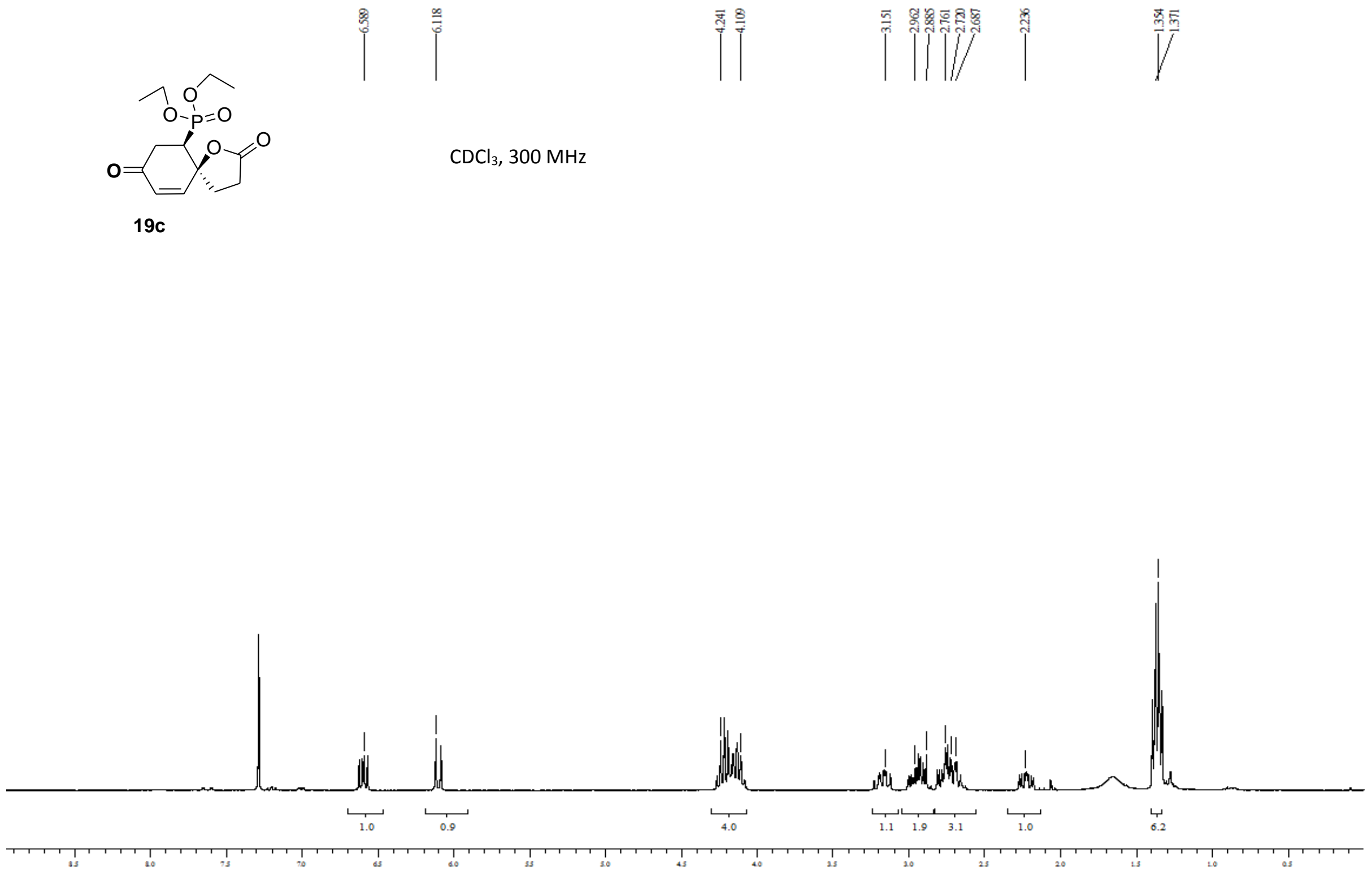


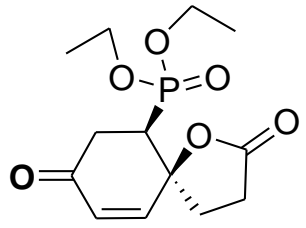

$19 c$ 


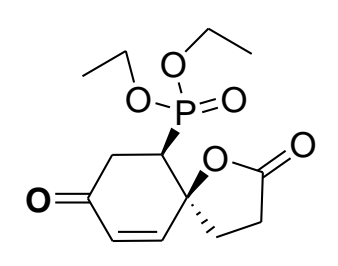

$\mathrm{CDCl}_{3}, 122 \mathrm{MHz}$

$19 c$

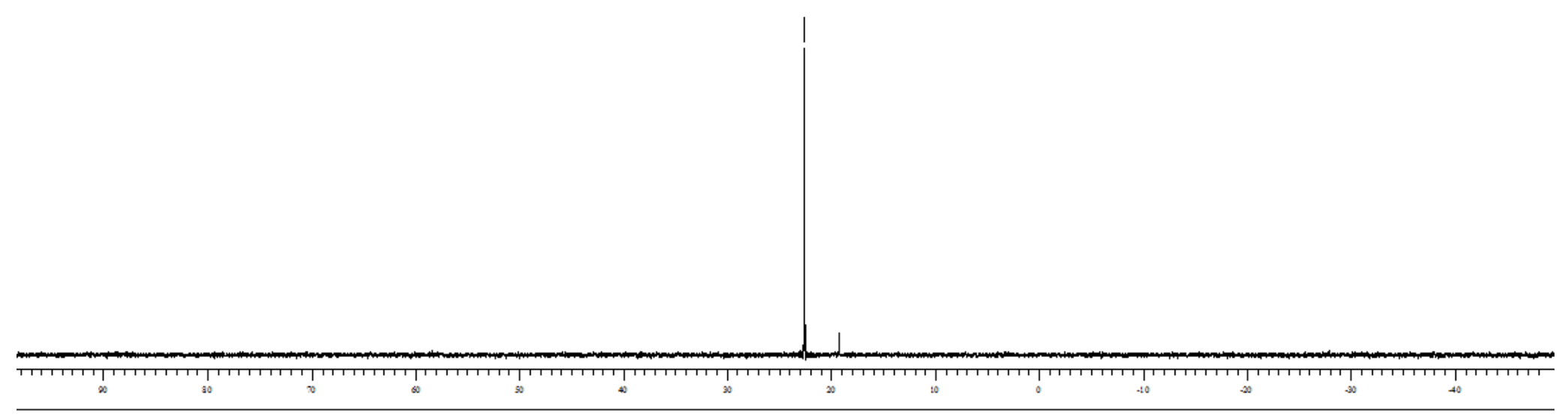



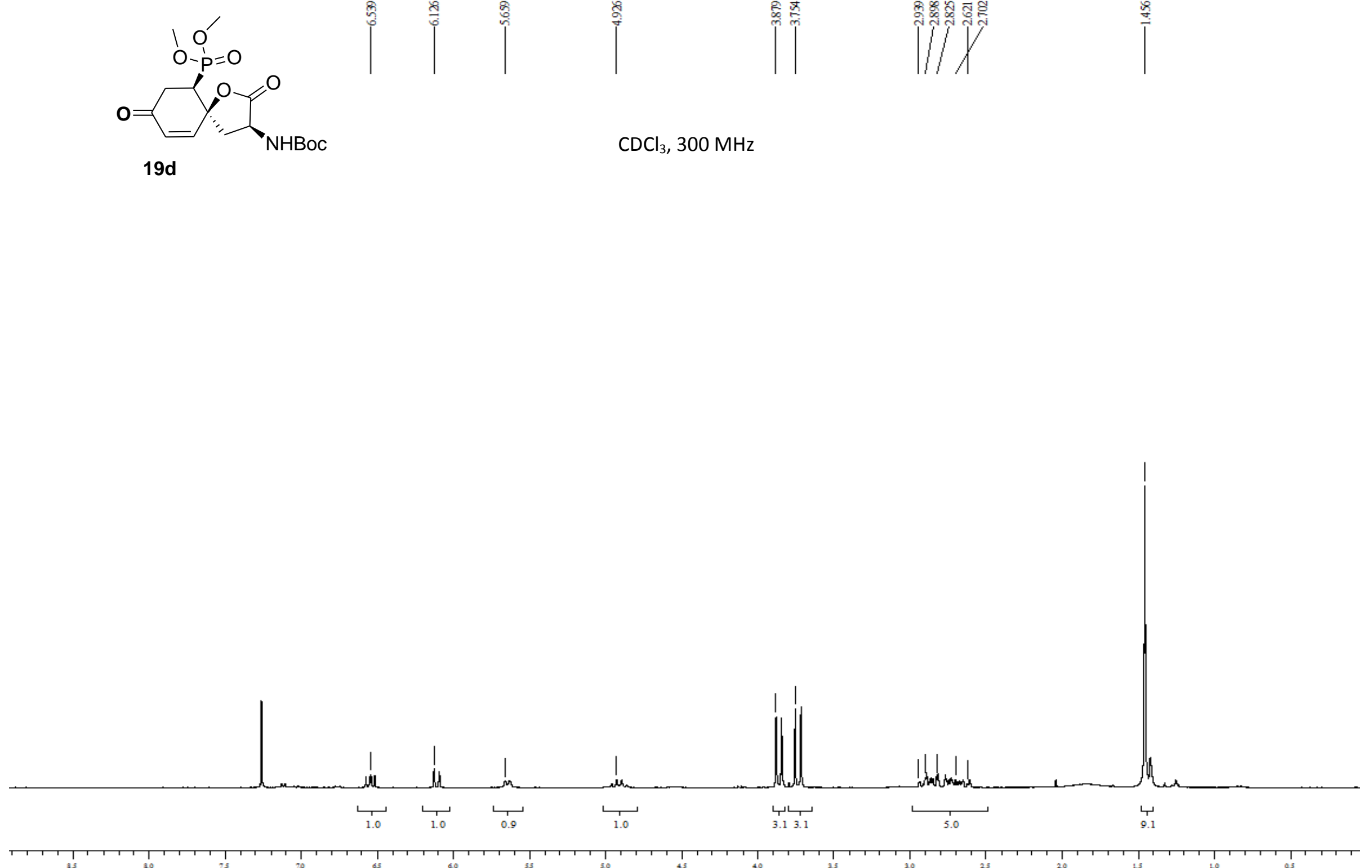


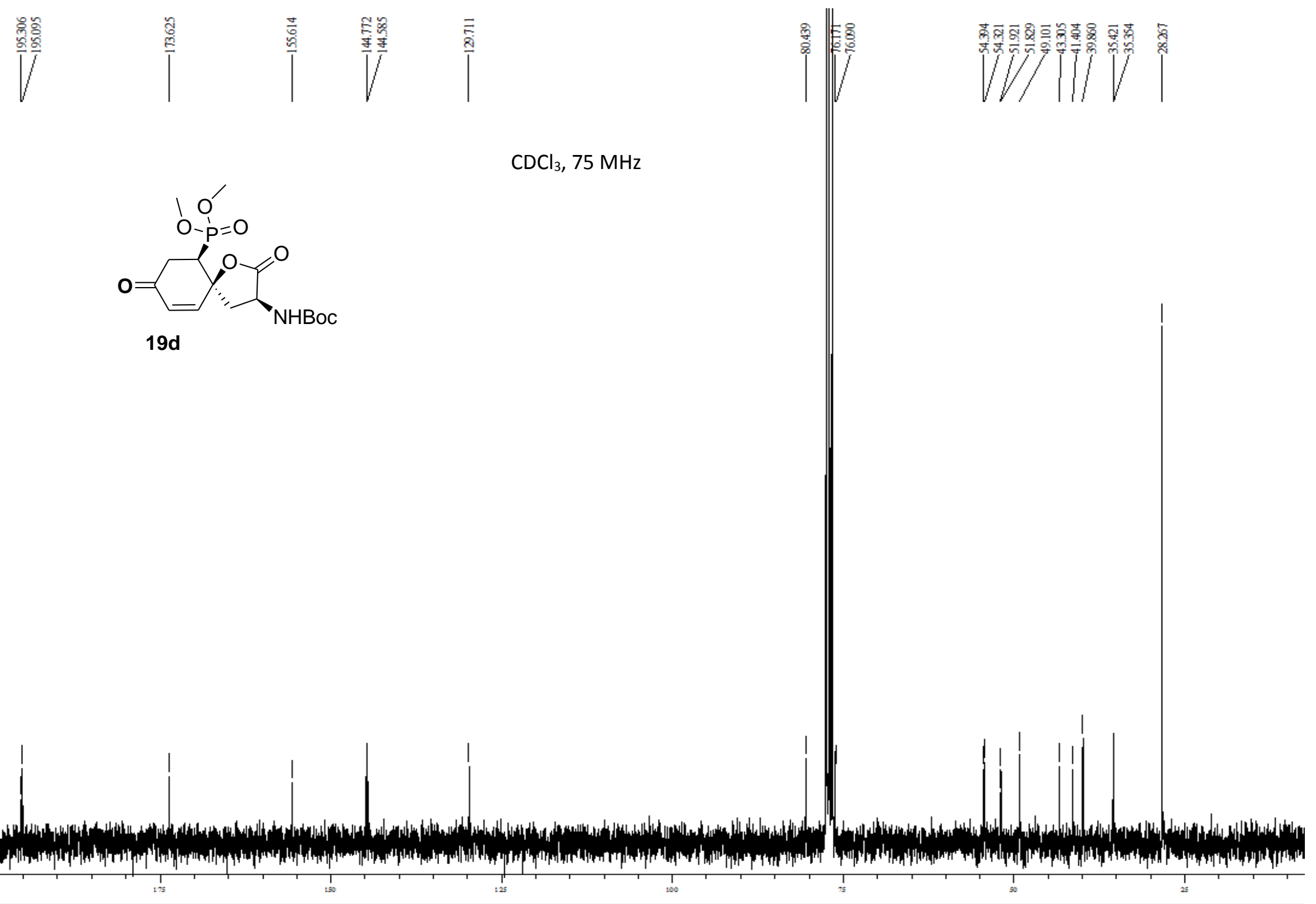



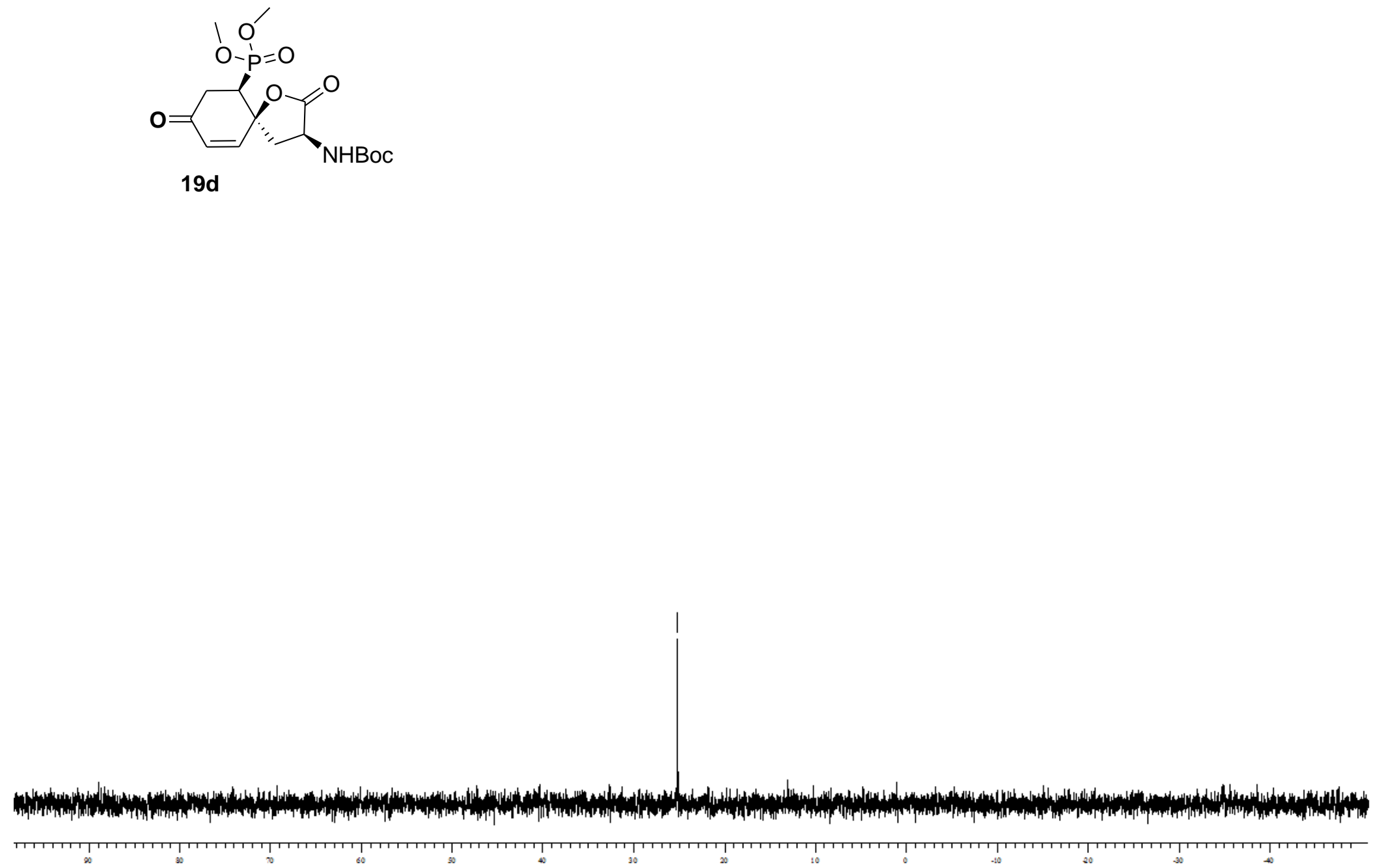


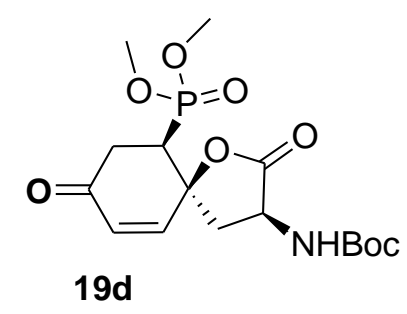

$\mathrm{CDCl}_{3}, 300 \mathrm{MHz}$

NOE, $t$-Bu

irradiation

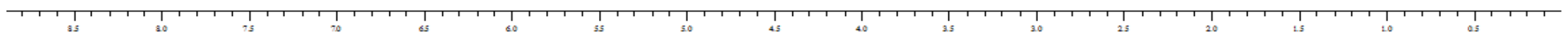



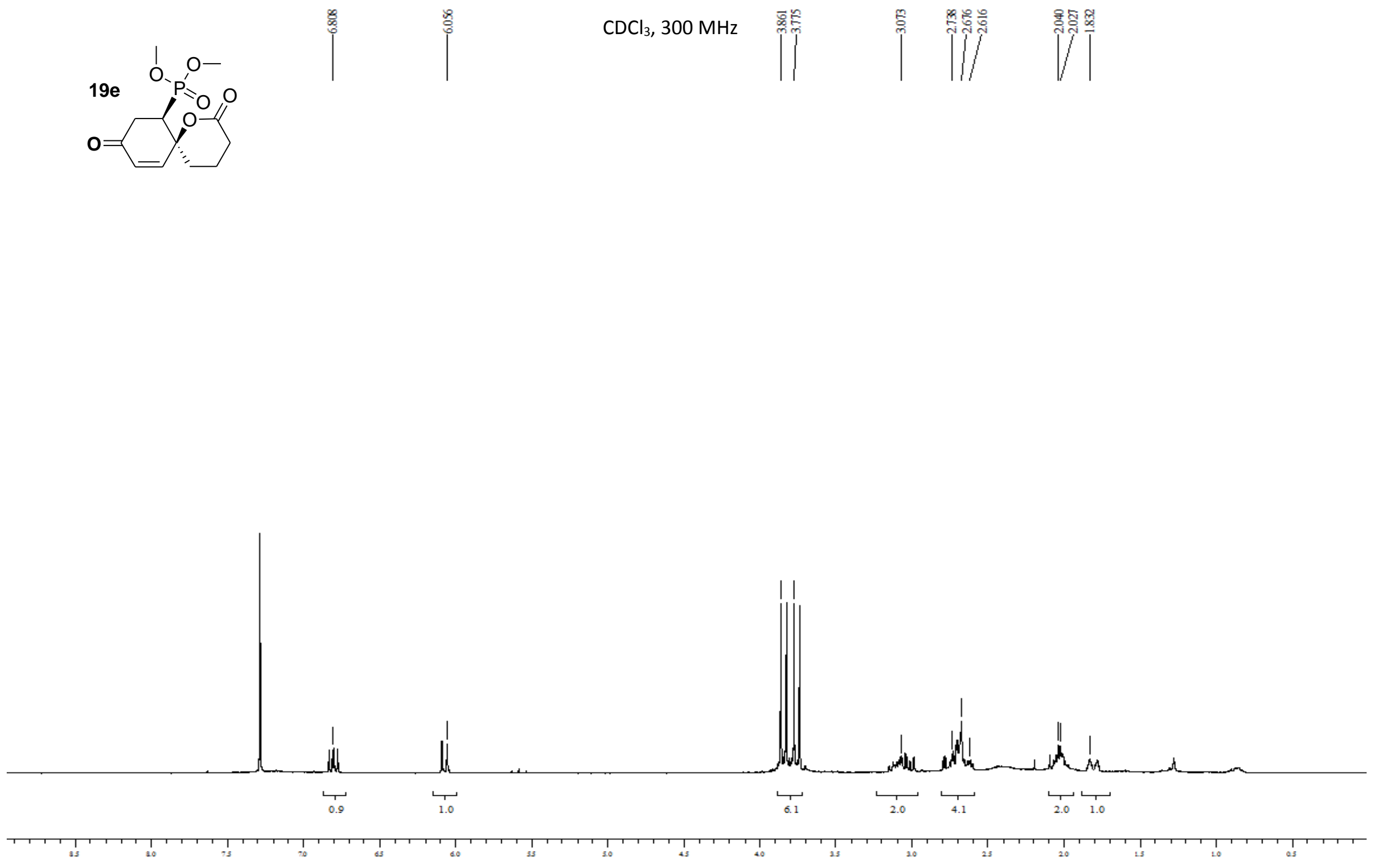

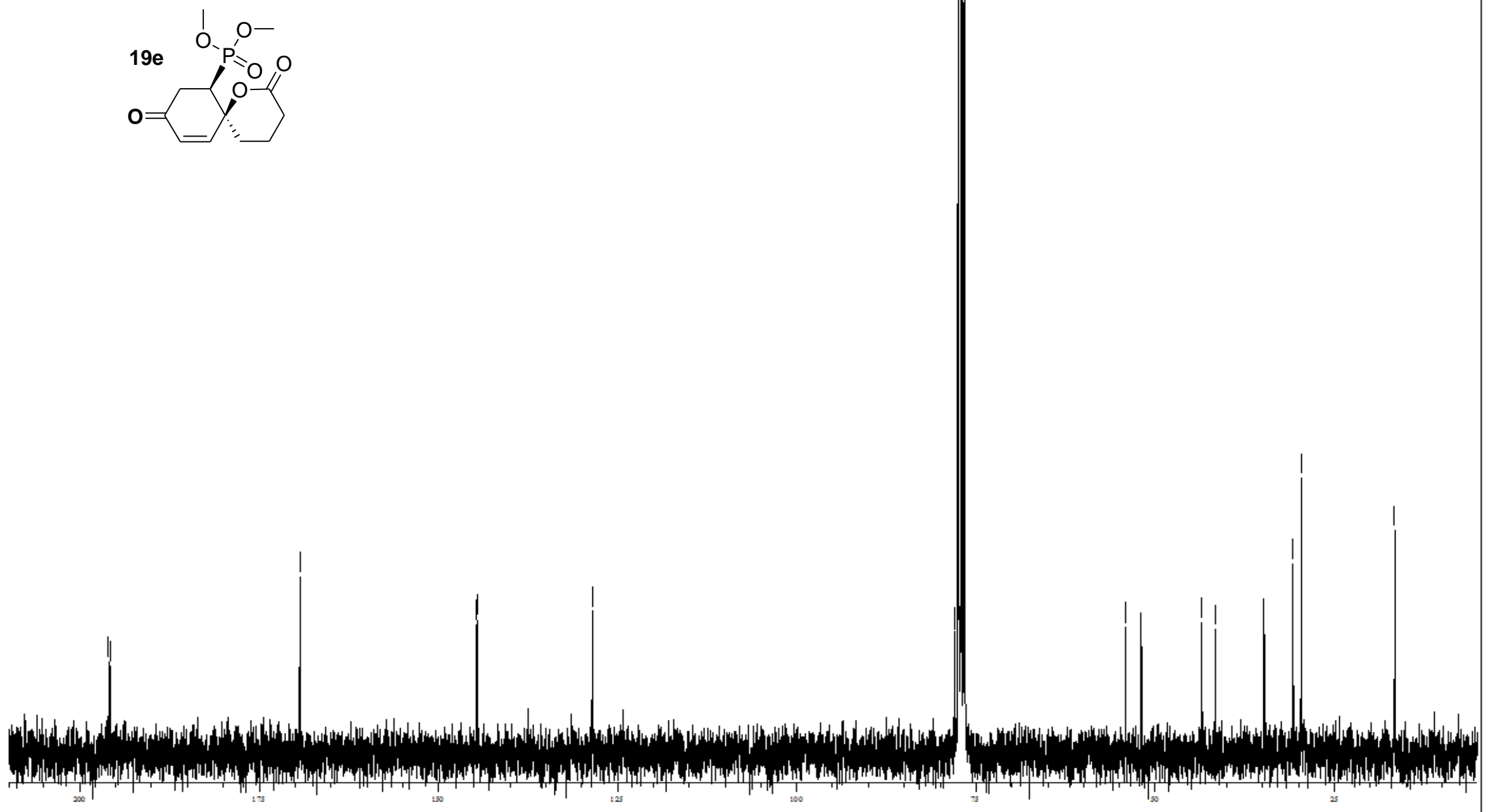


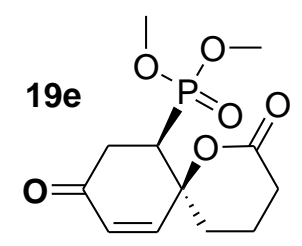

$\mathrm{CDCl}_{3}, 122 \mathrm{MHz}$

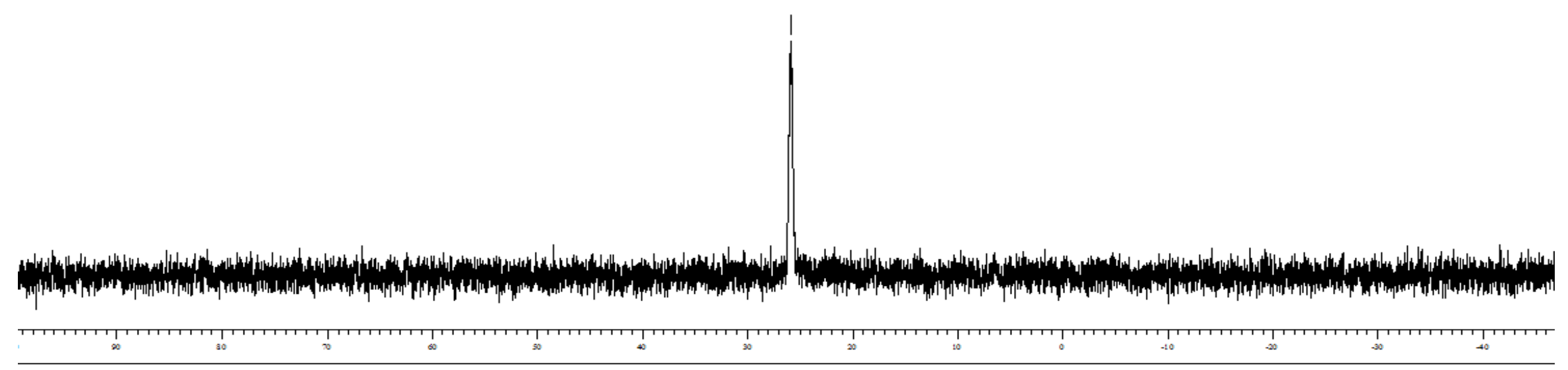



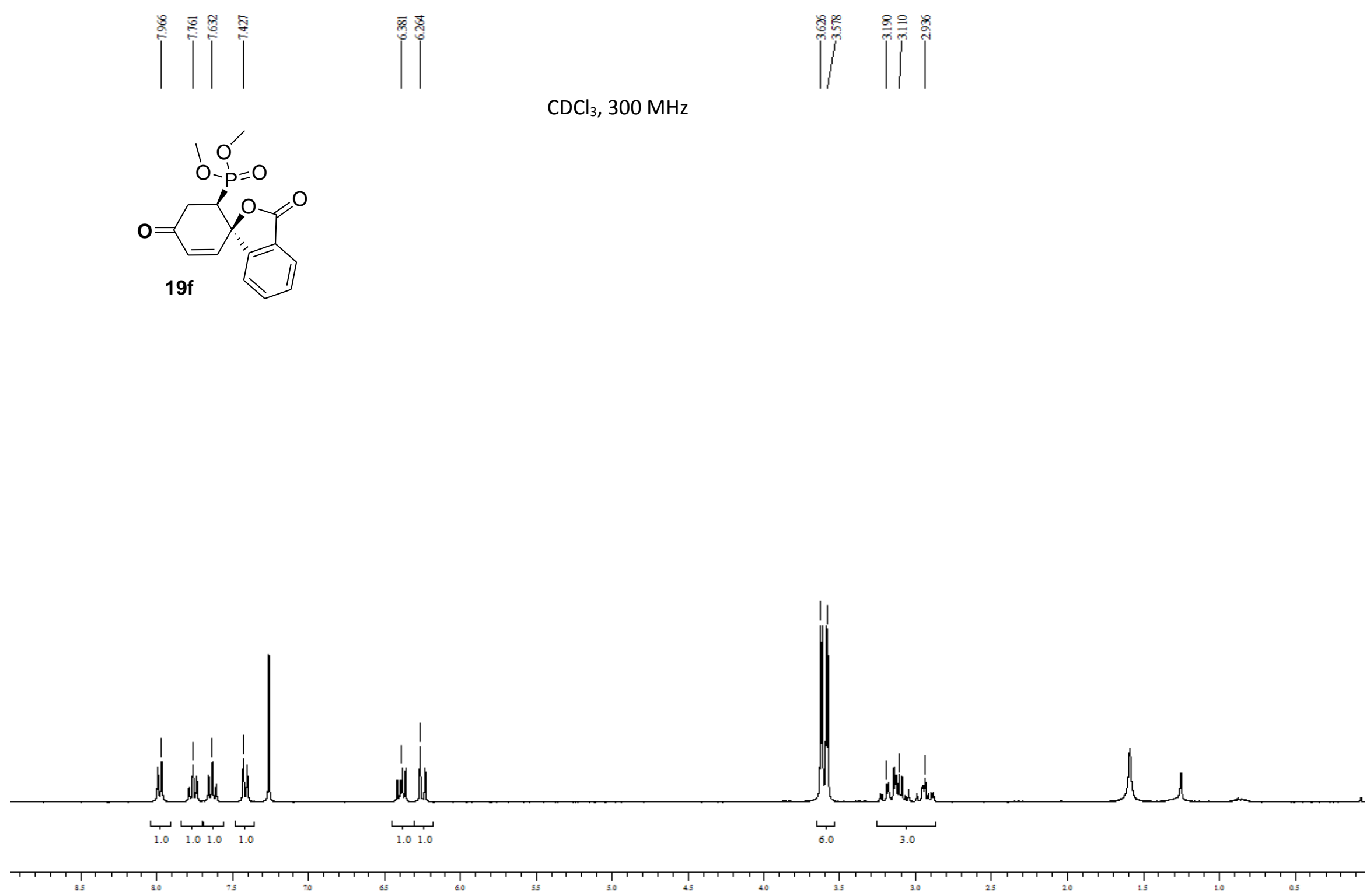
$\sqrt{3}$
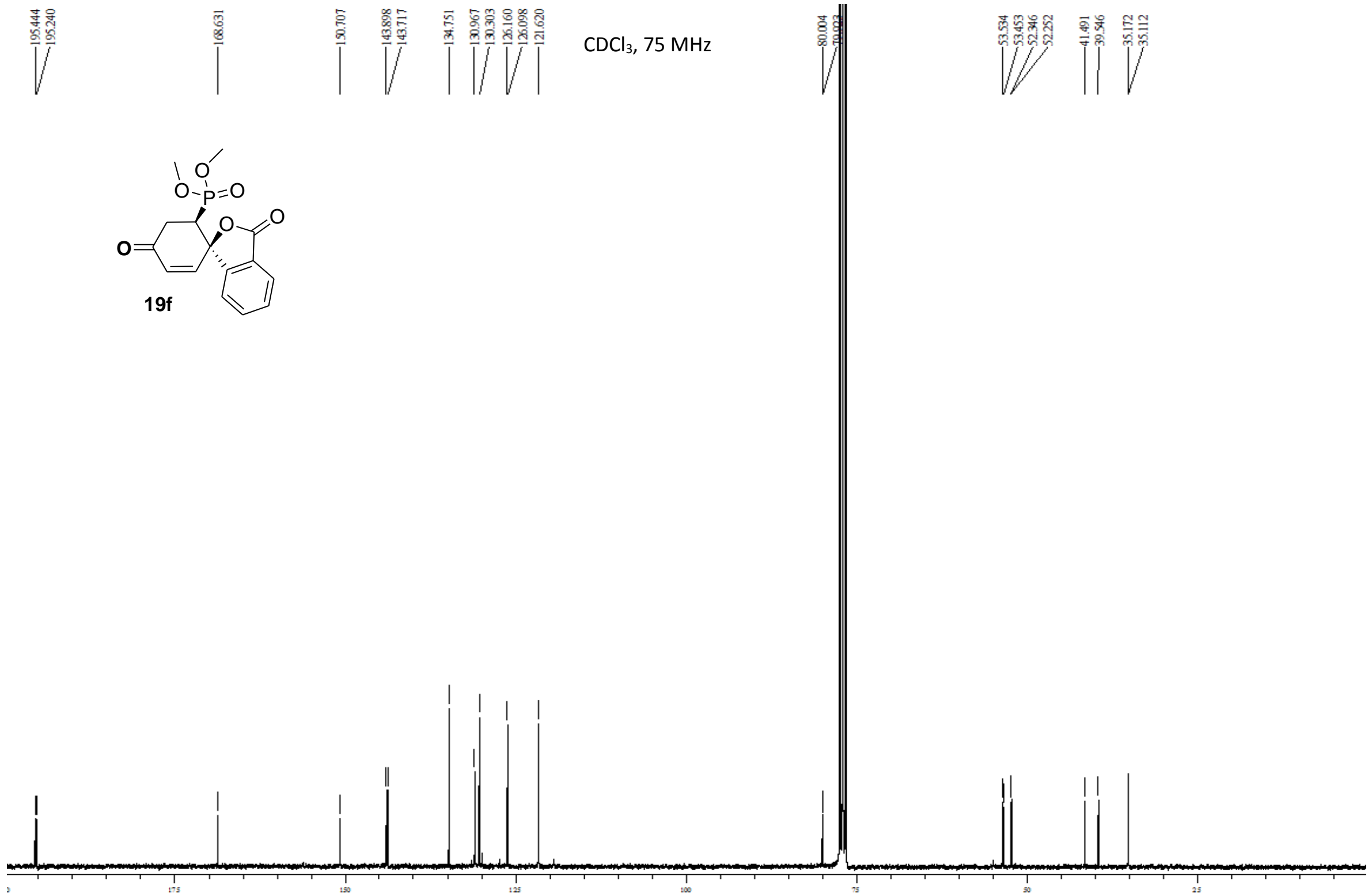

S24 
$\mathrm{CDCl}_{3}, 122 \mathrm{MHz}$

กับ
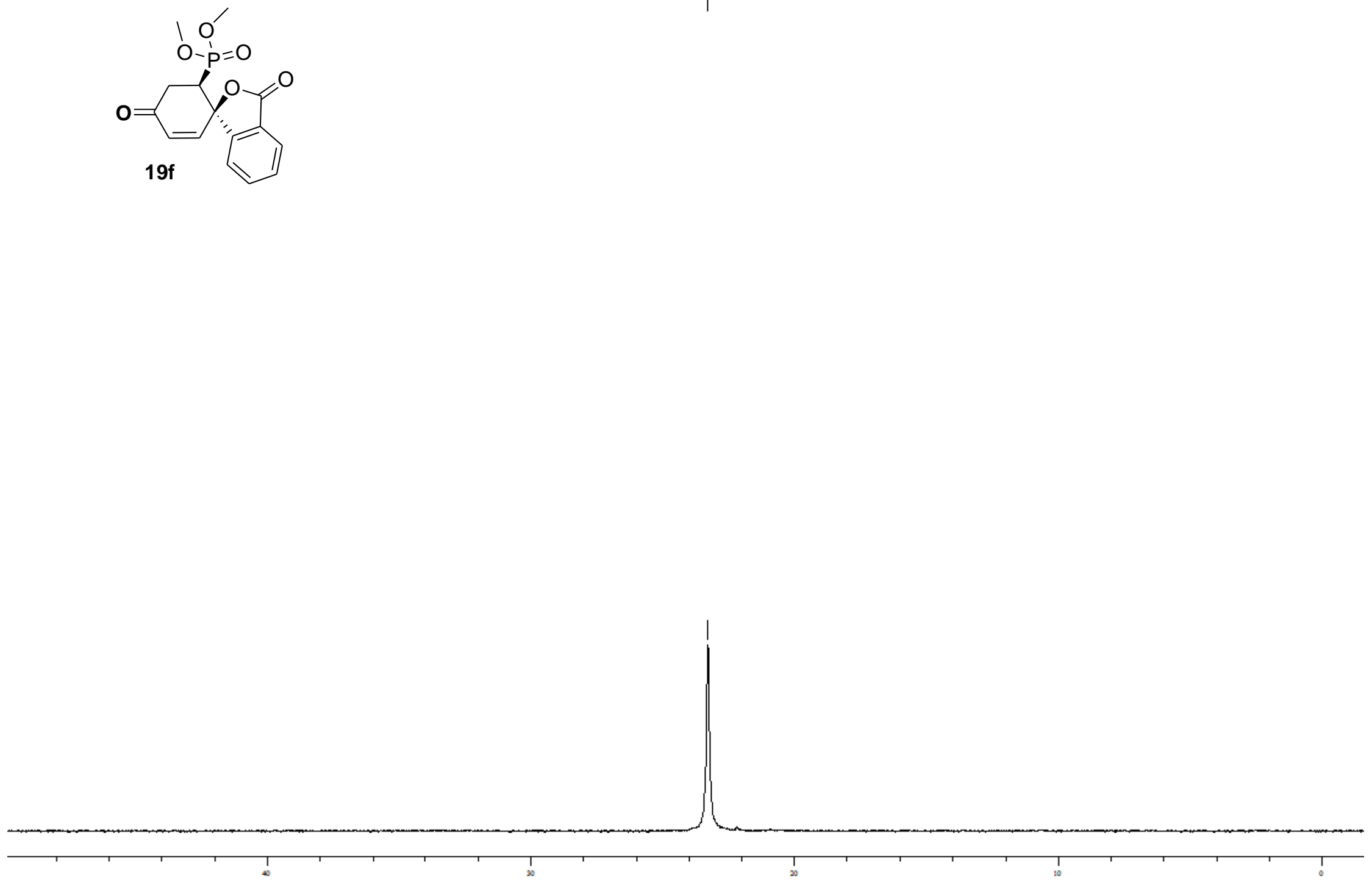

S25 


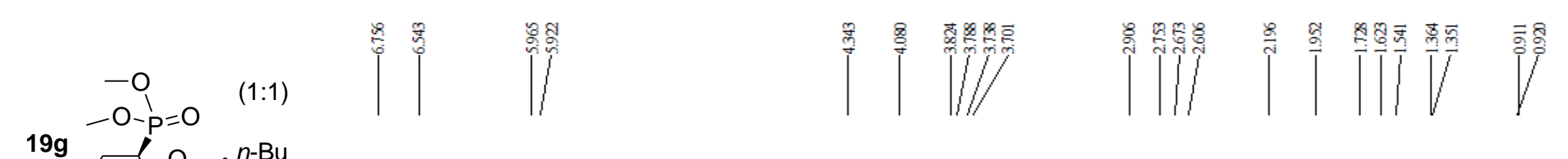

$\mathrm{CDCl}_{3}, 300 \mathrm{MHz}$

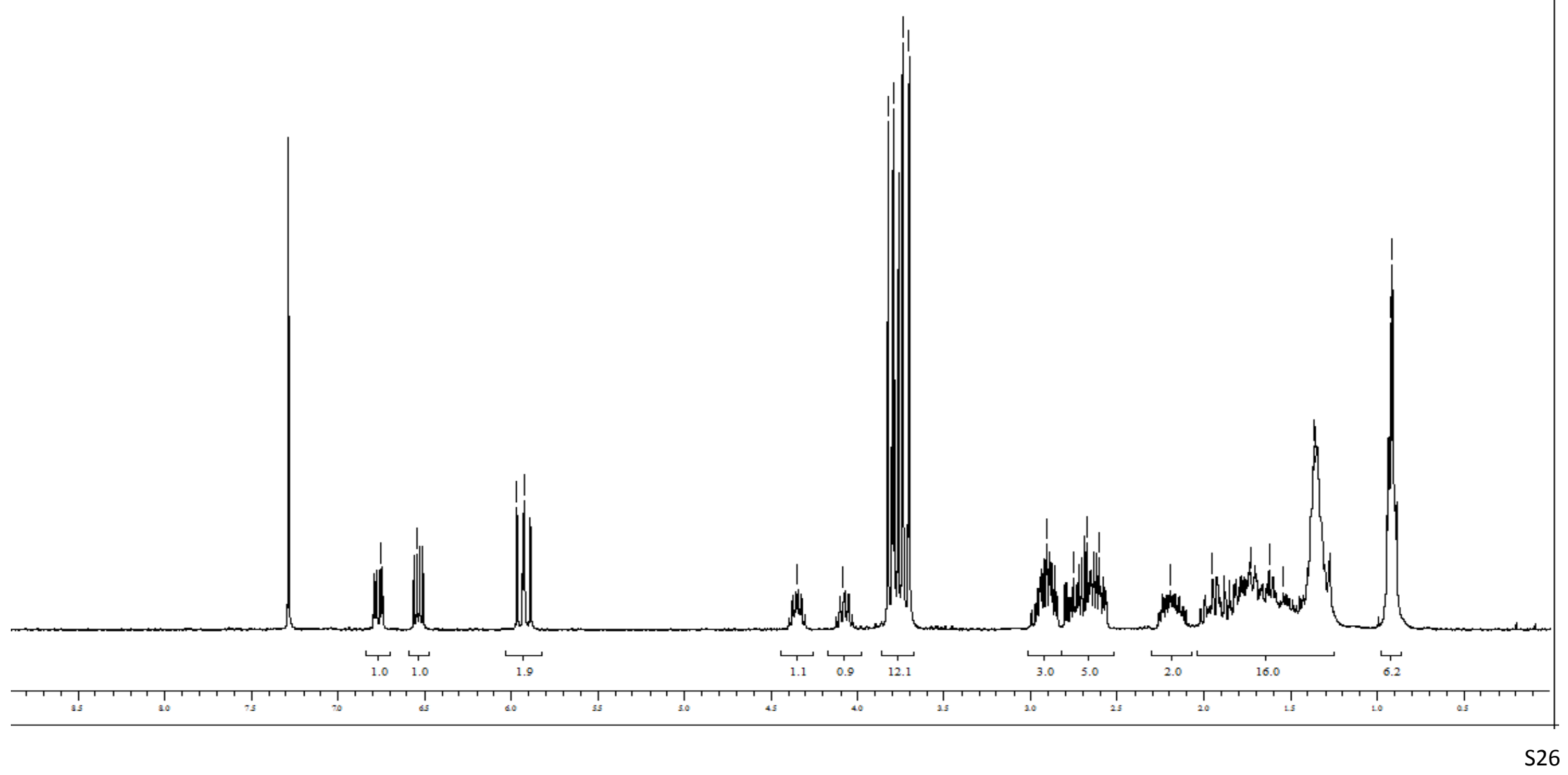




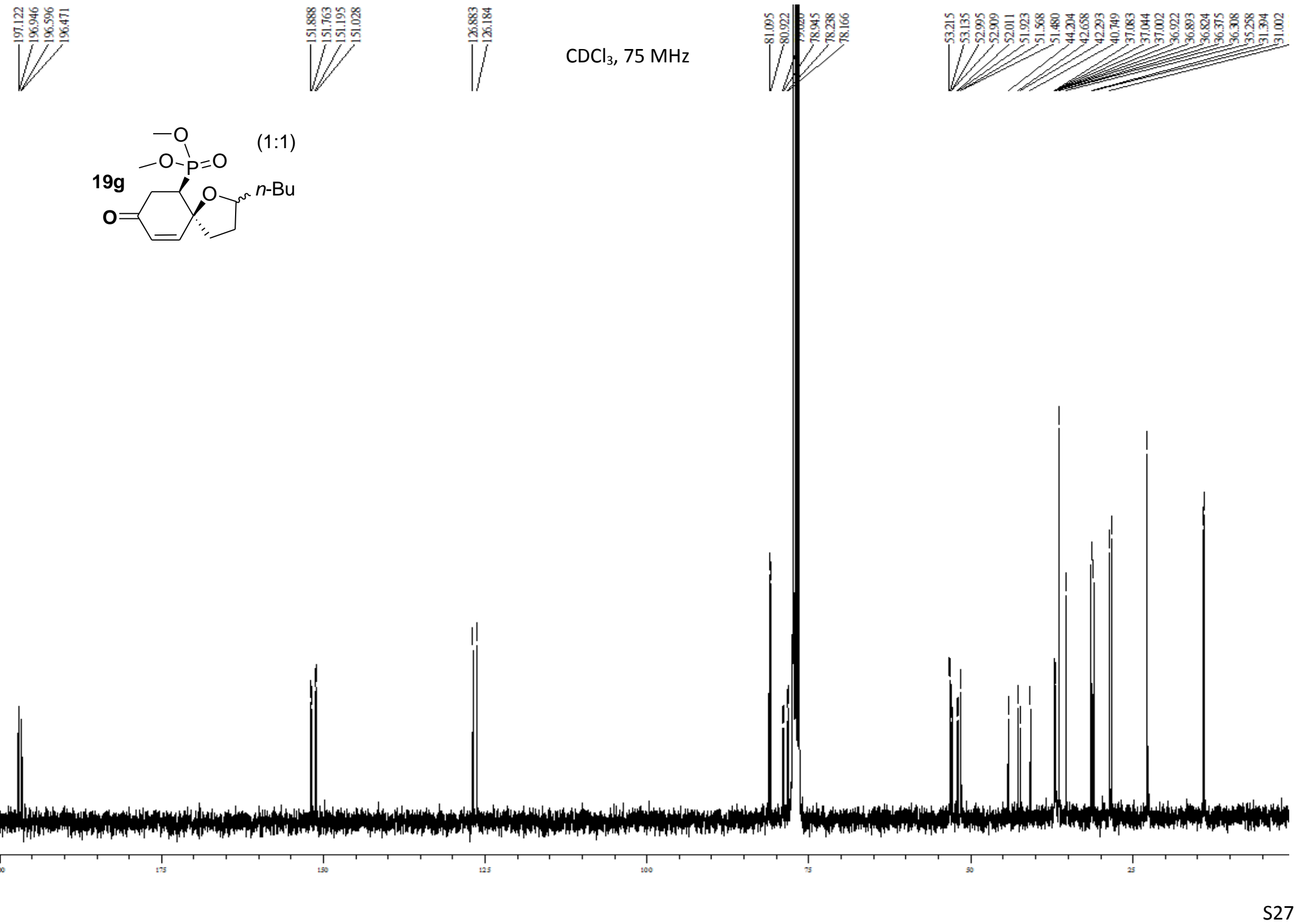



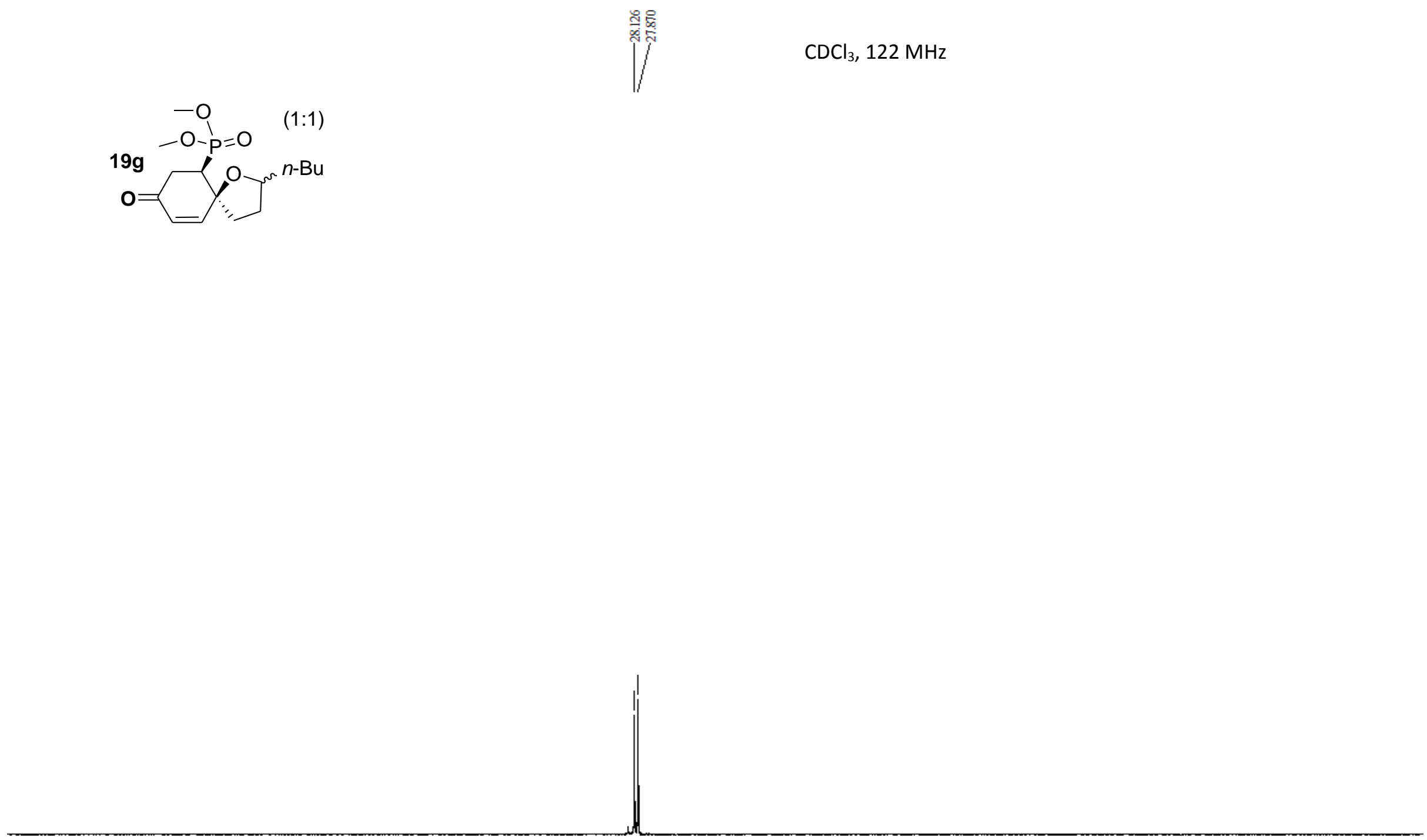


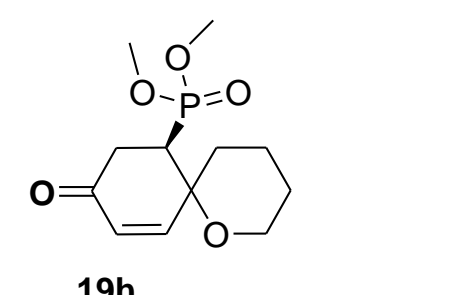

19h

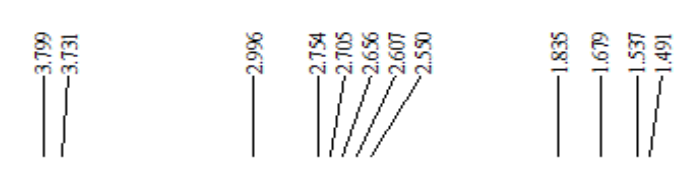

$\mathrm{CDCl}_{3}, 300 \mathrm{MHz}$

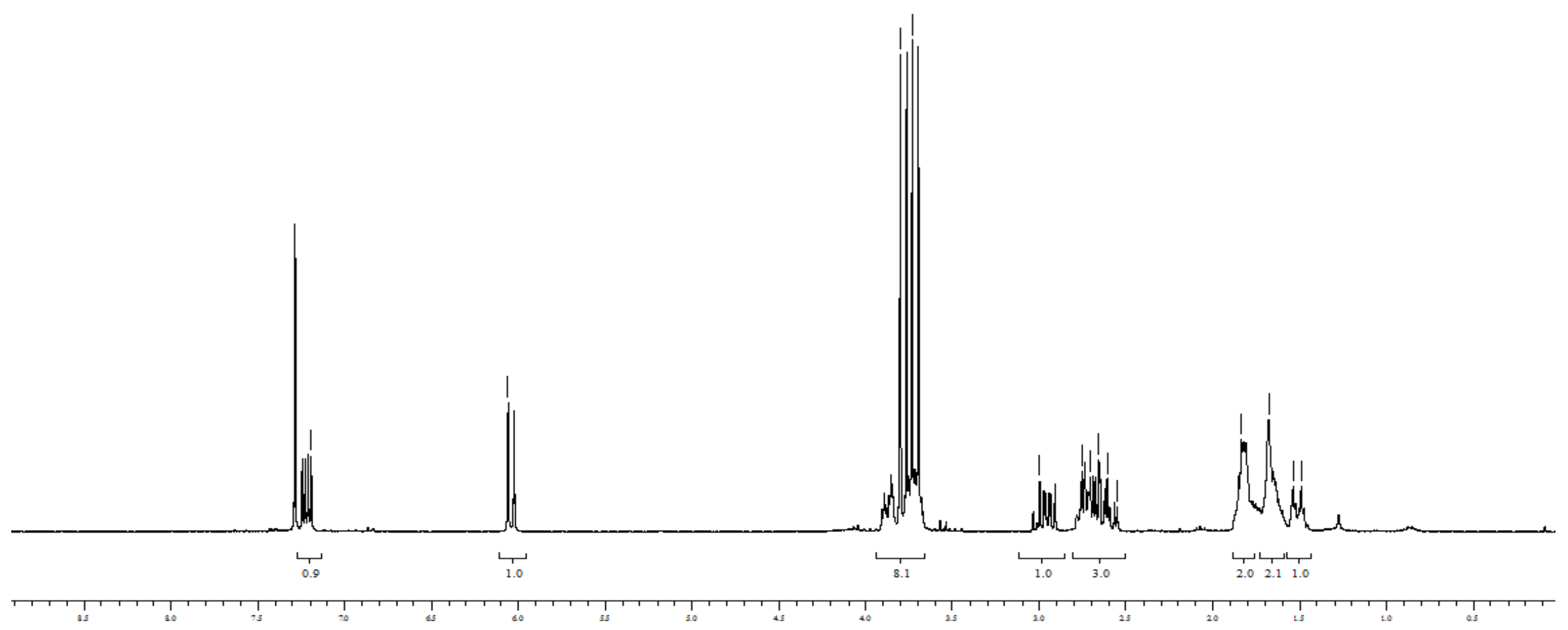




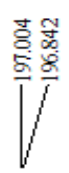

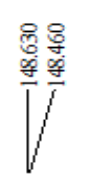

竞

$\sqrt{3}$
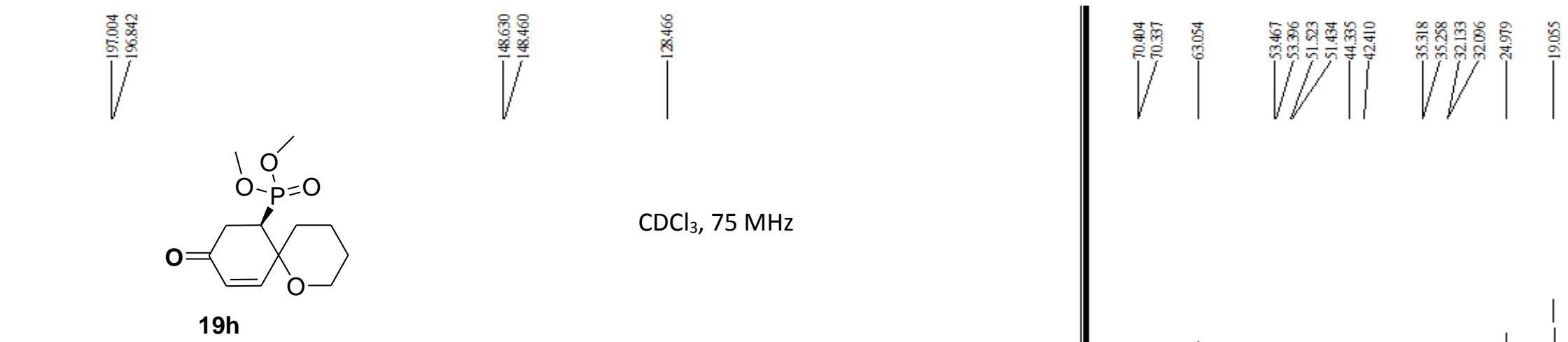

$\mathrm{CDCl}_{3}, 75 \mathrm{MHz}$

19h
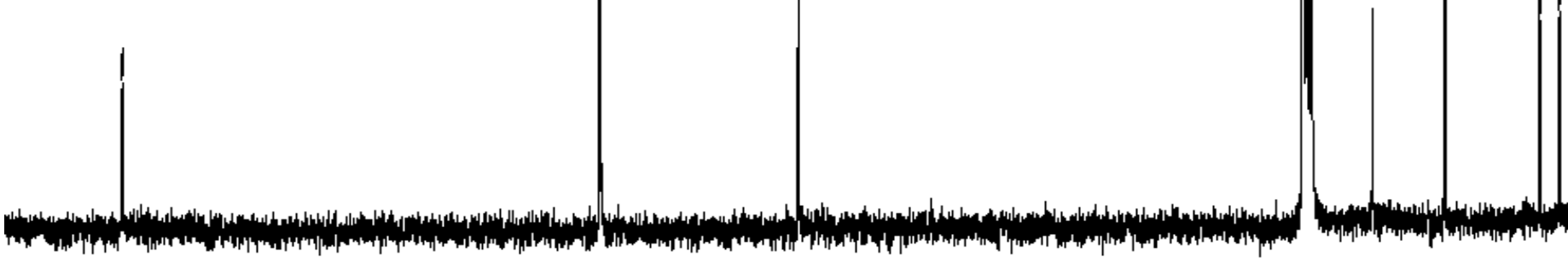

$\mid$

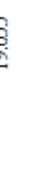

S30 


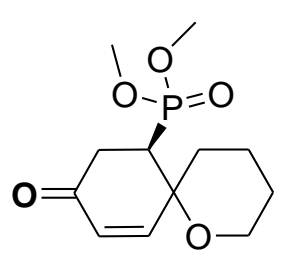

$\mathrm{CDCl}_{3}, 122 \mathrm{MHz}$

19h

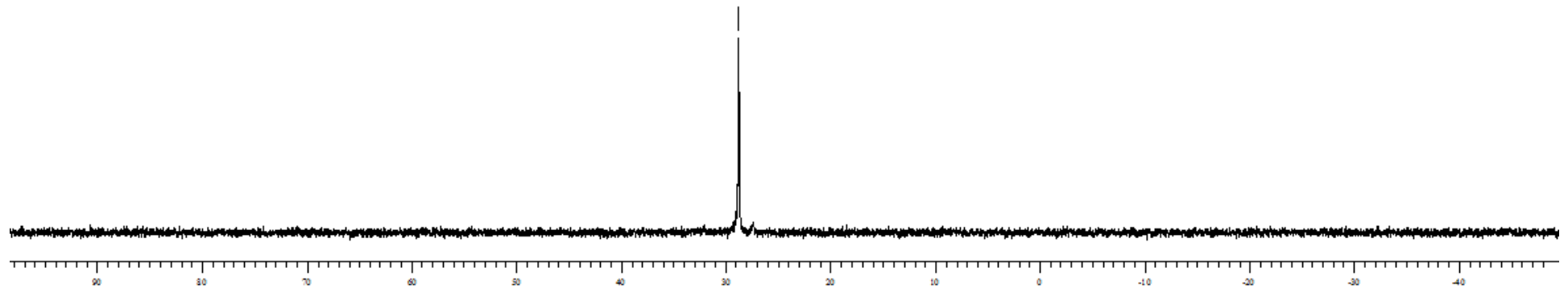




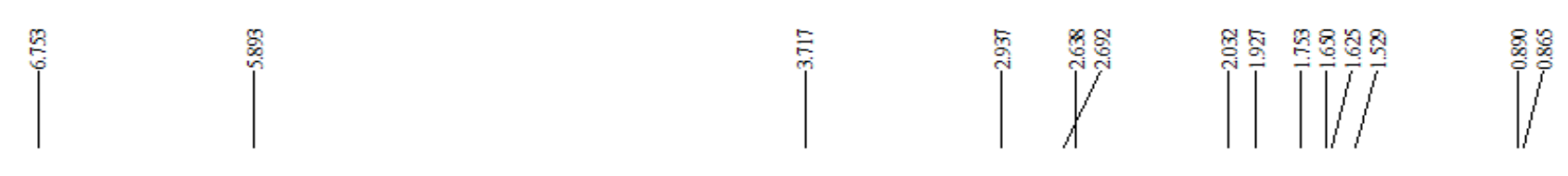

$\mathrm{CDCl}_{3}, 300 \mathrm{MHz}$
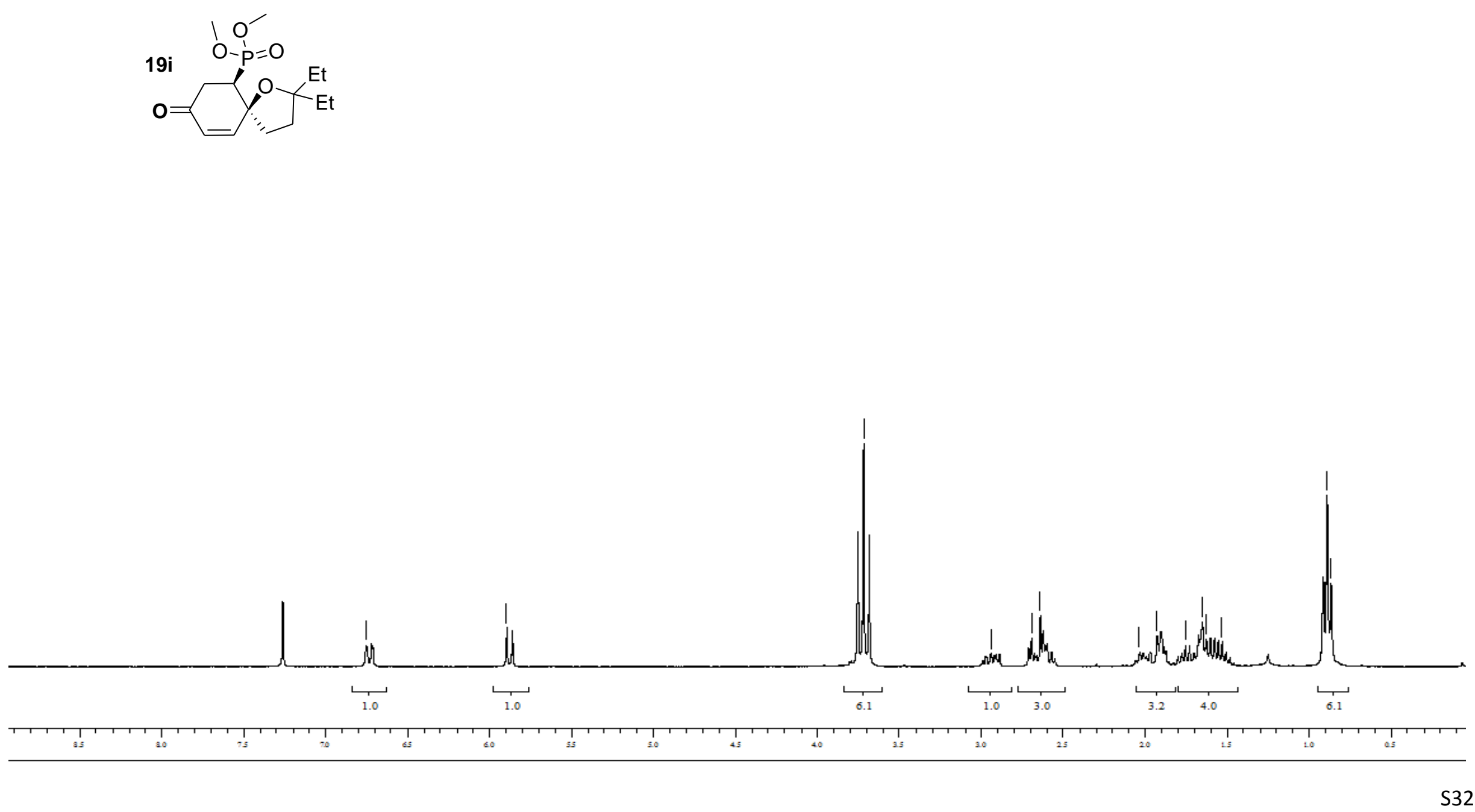
y

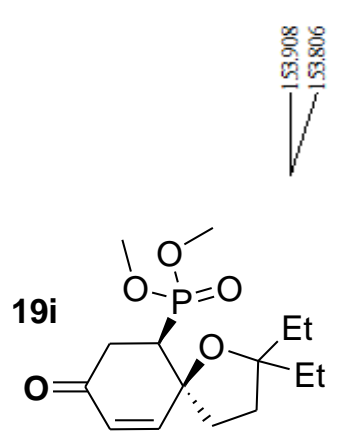

$\mathrm{CDCl}_{3}, 75 \mathrm{MHz}$

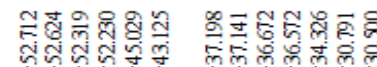

$1 / 4$

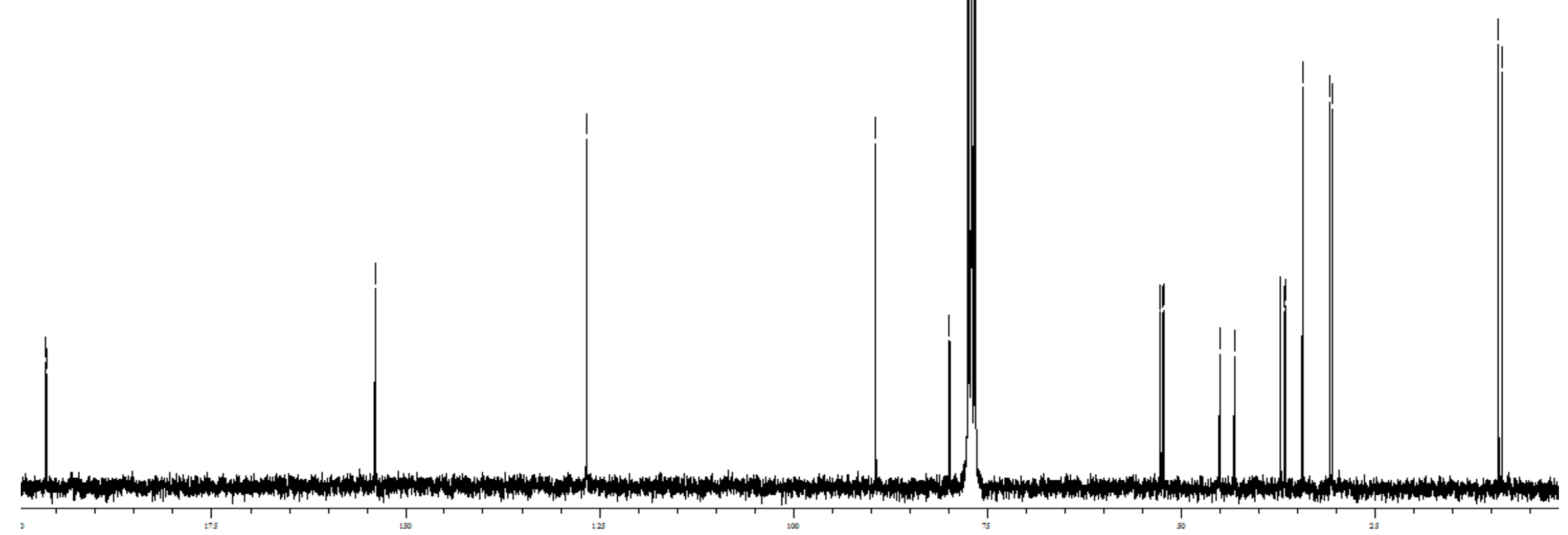




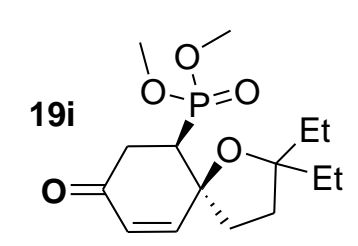

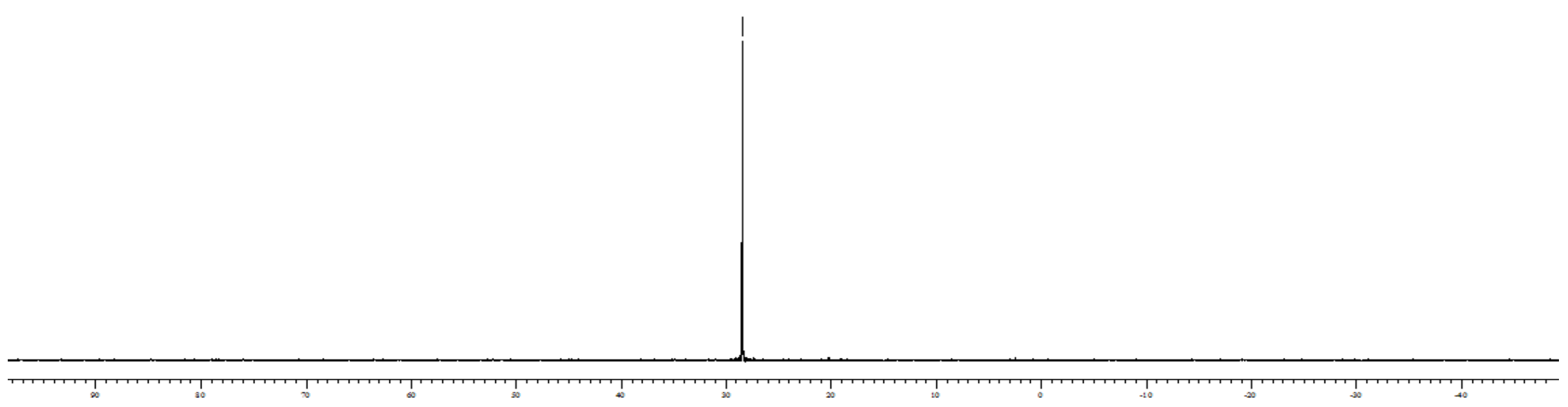




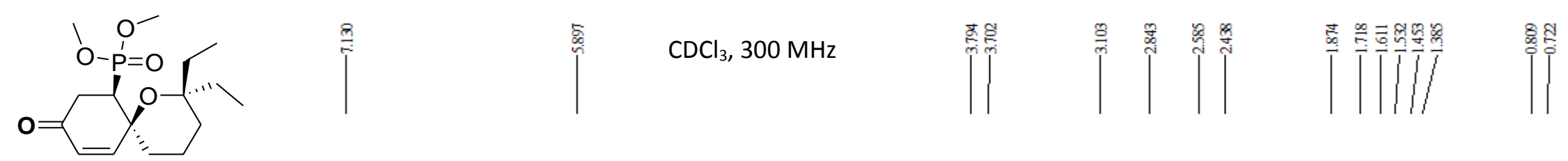

19j

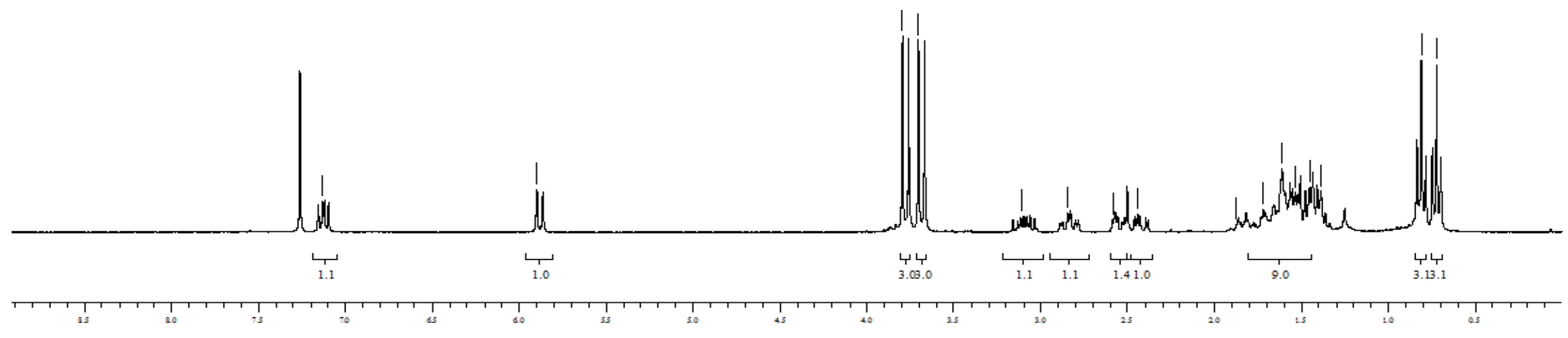




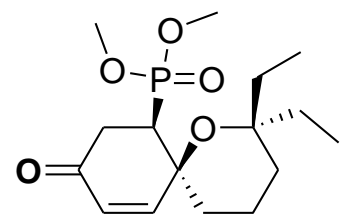

19j 
$\mathrm{CDCl}_{3}, 122 \mathrm{MHz}$

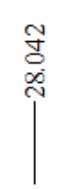

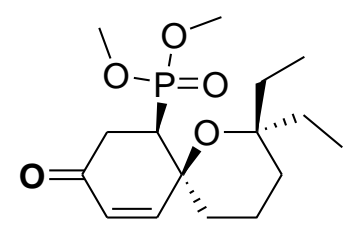

19j

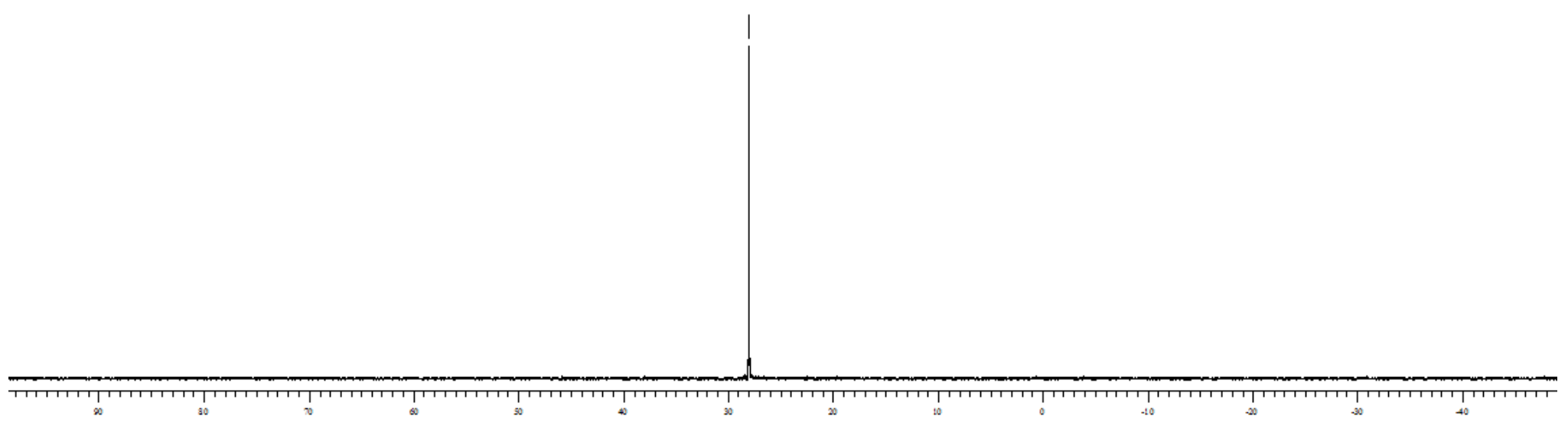

S37 


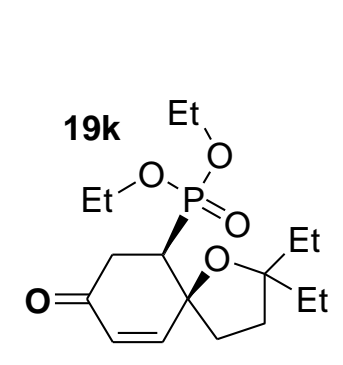

$\mathrm{CDCl}_{3}, 300 \mathrm{MHz}$

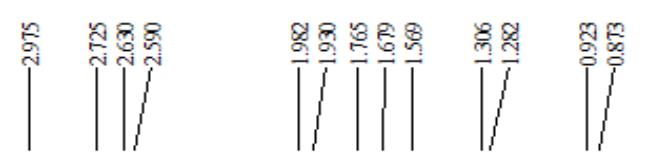

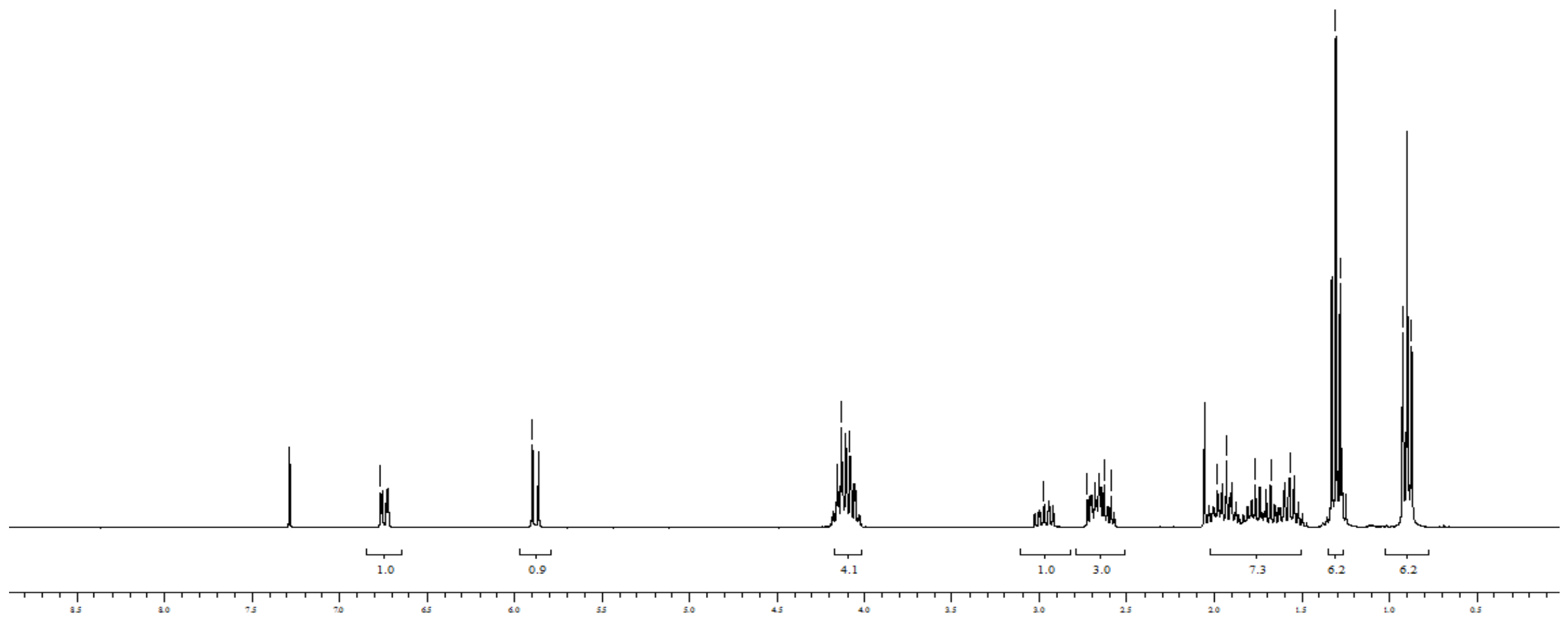



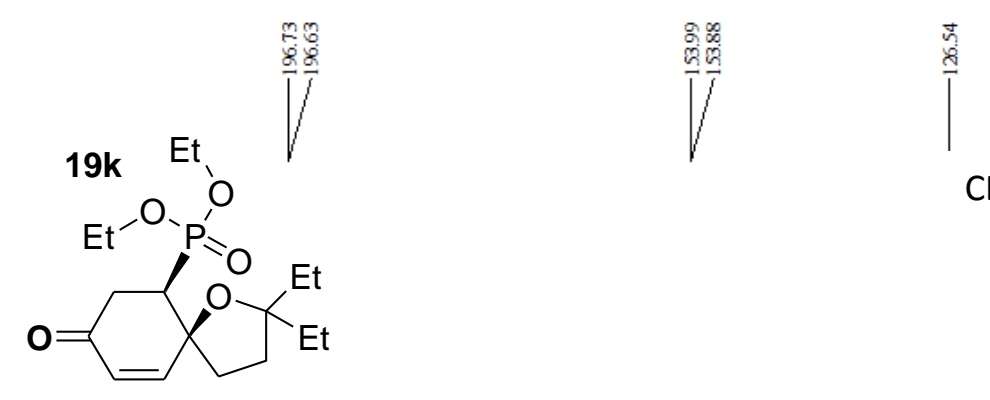

$\mathrm{CDCl}_{3}, 75 \mathrm{MHz}$

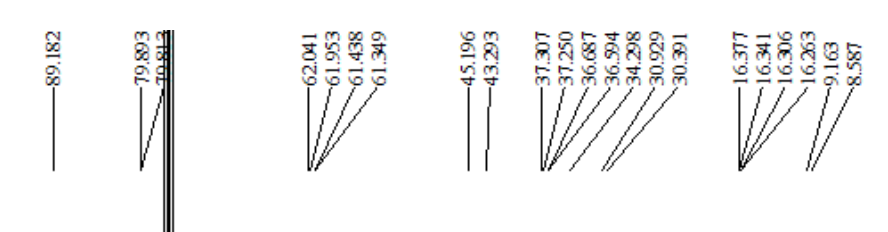



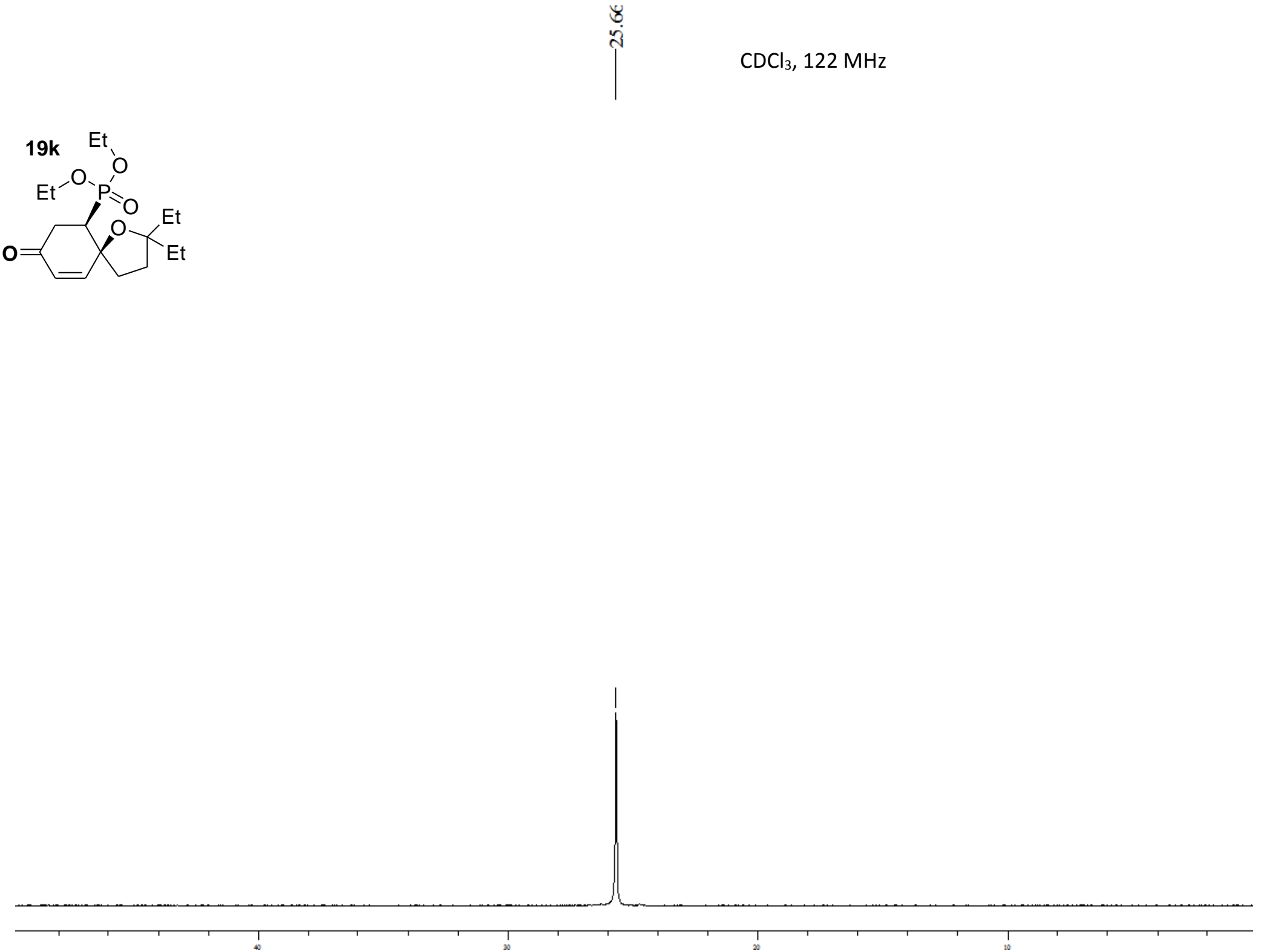


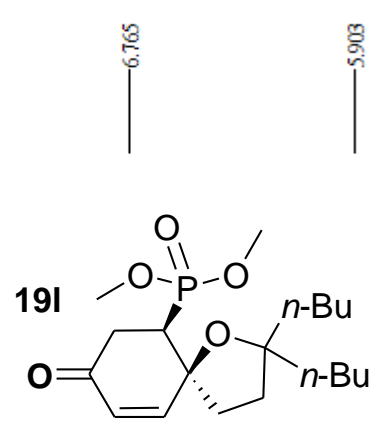

$\mathrm{CDCl}_{3}, 300 \mathrm{MHz}$

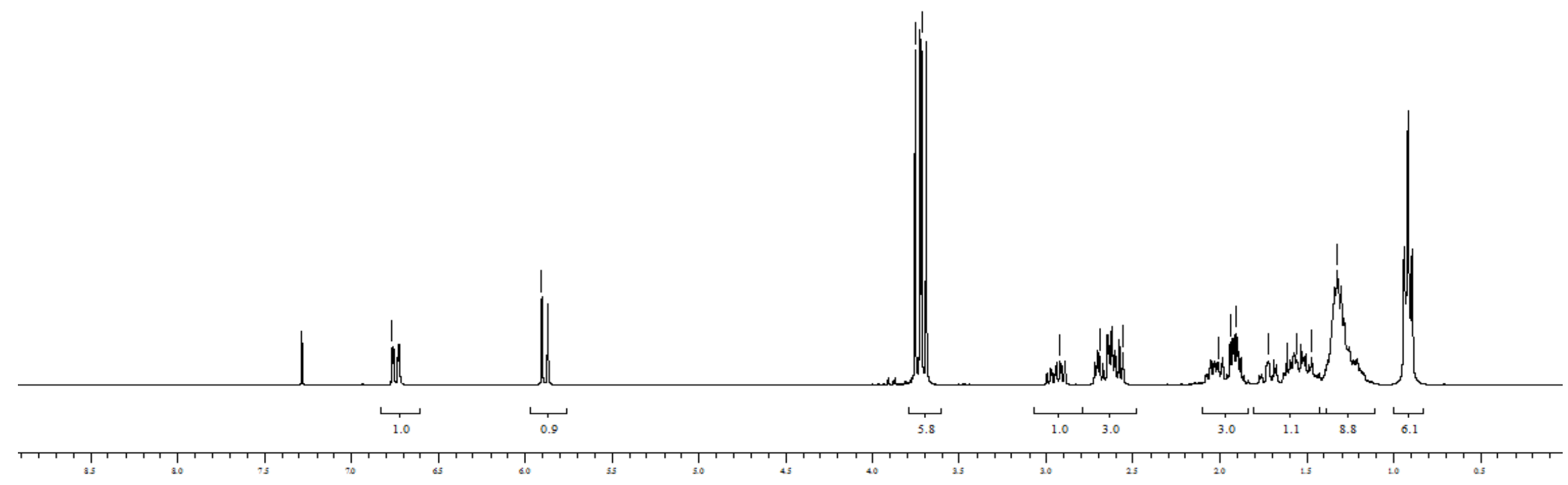


y

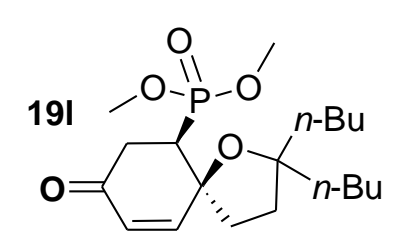




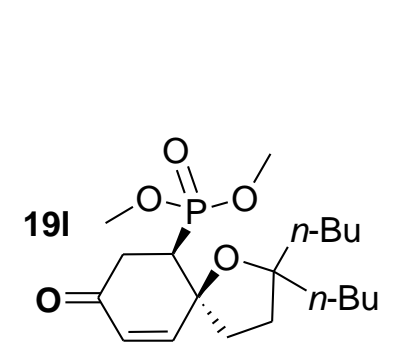

\section{$\mathrm{CDCl}_{3}, 122 \mathrm{MHz}$}

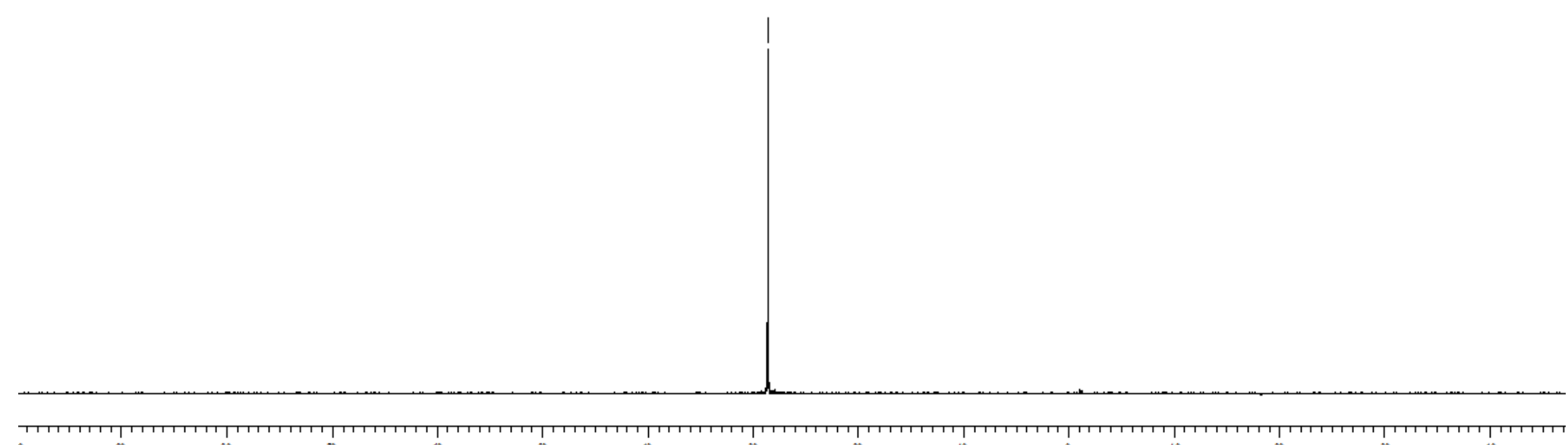



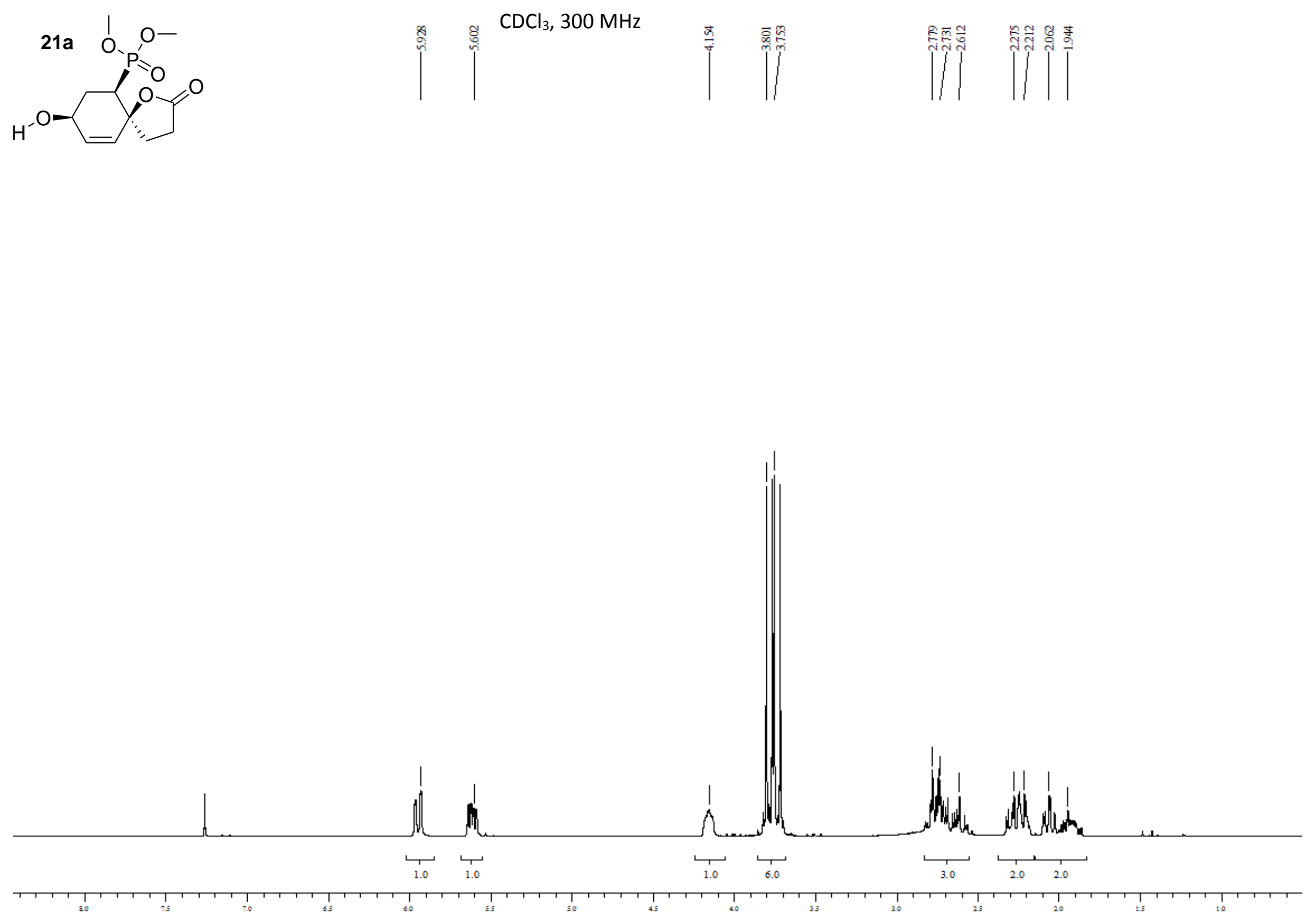


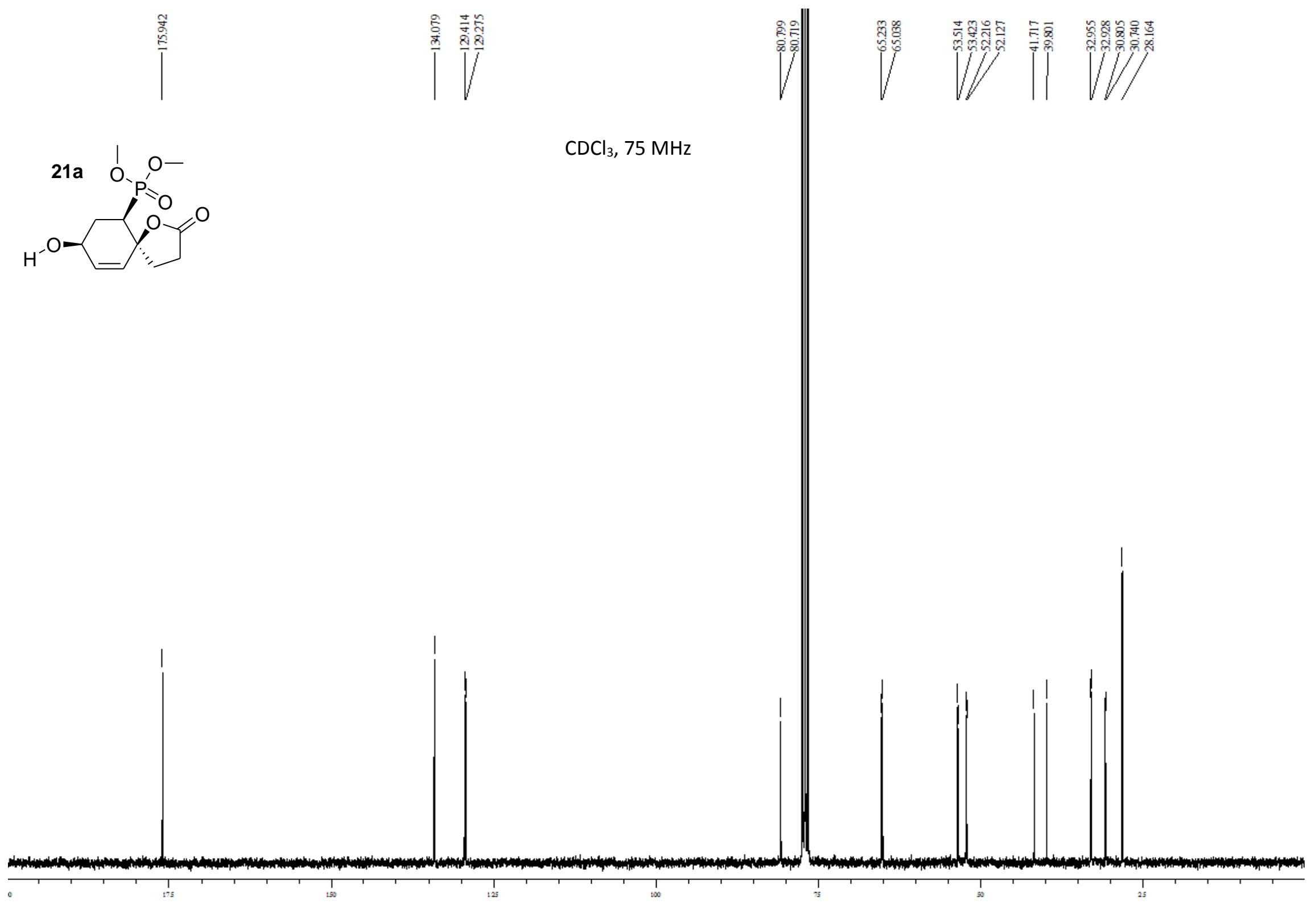




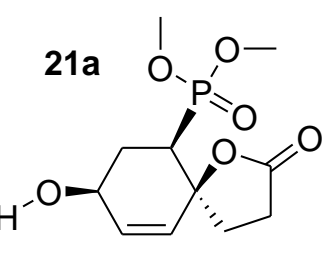

$\mathrm{CDCl}_{3}, 122 \mathrm{MHz}$

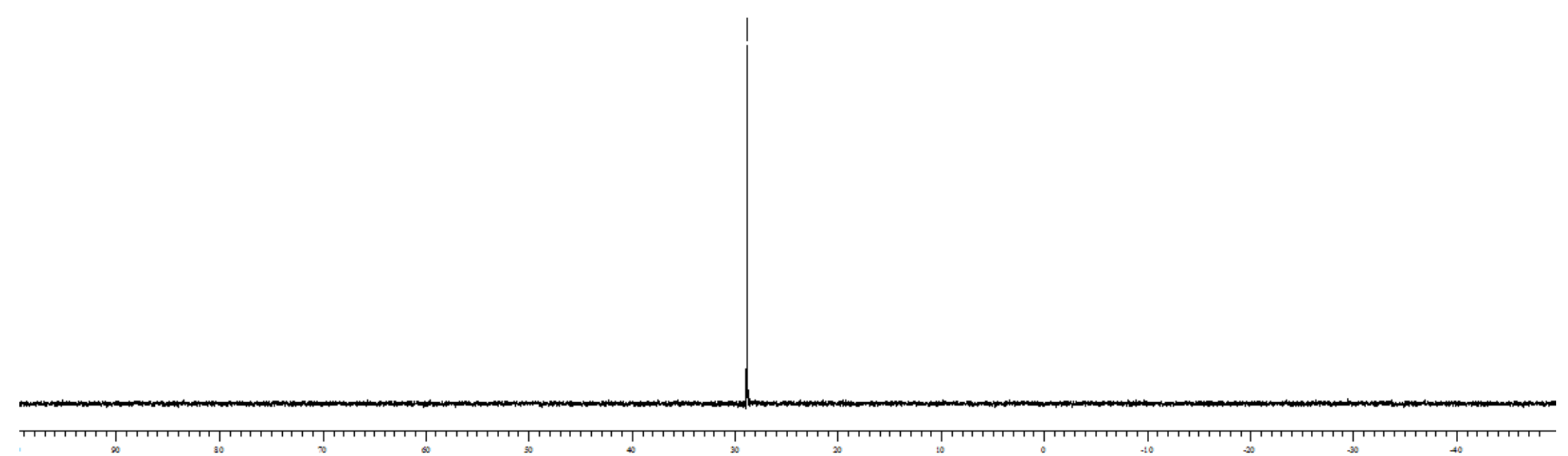



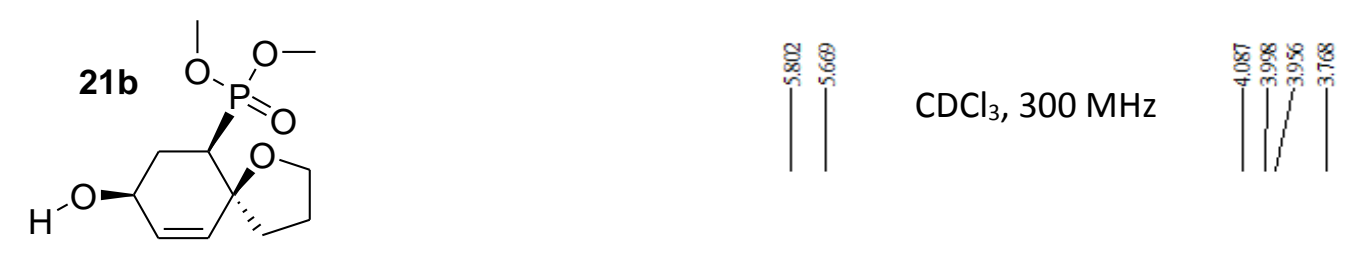

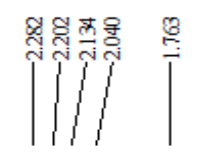

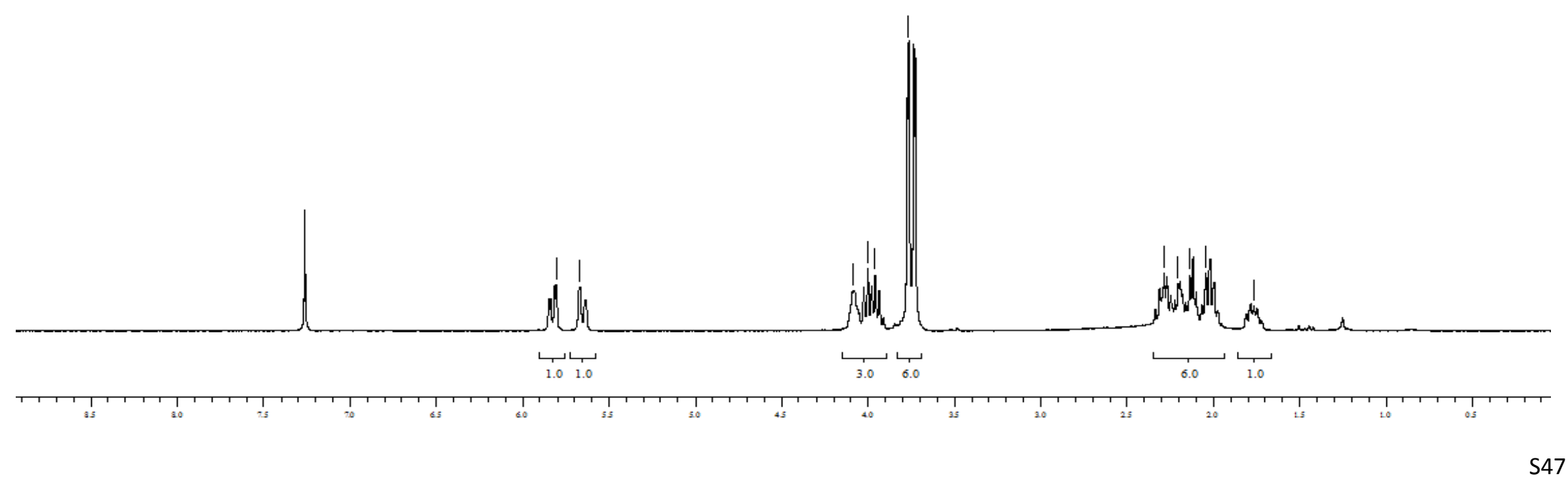



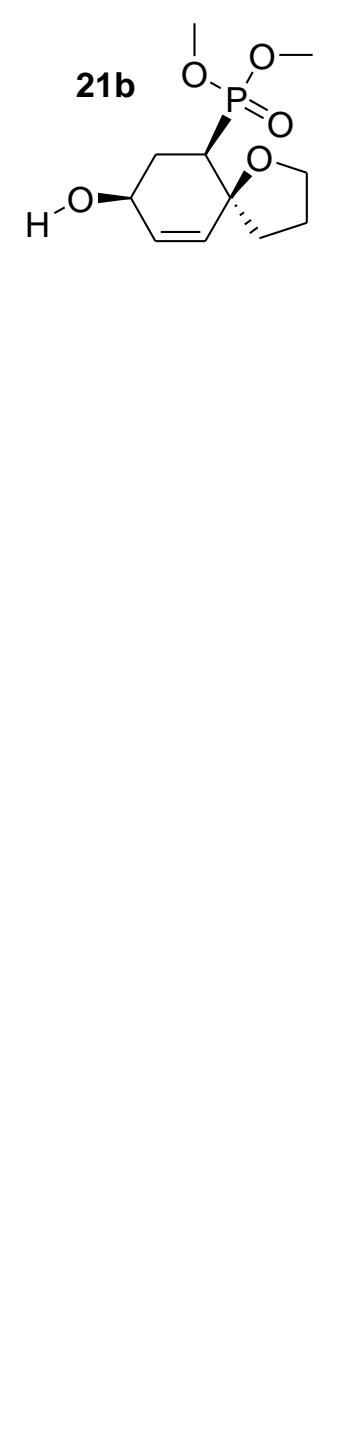


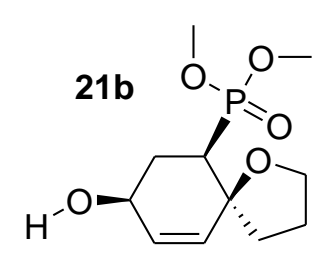

$\mathrm{CDCl}_{3}, 122 \mathrm{MHz}$

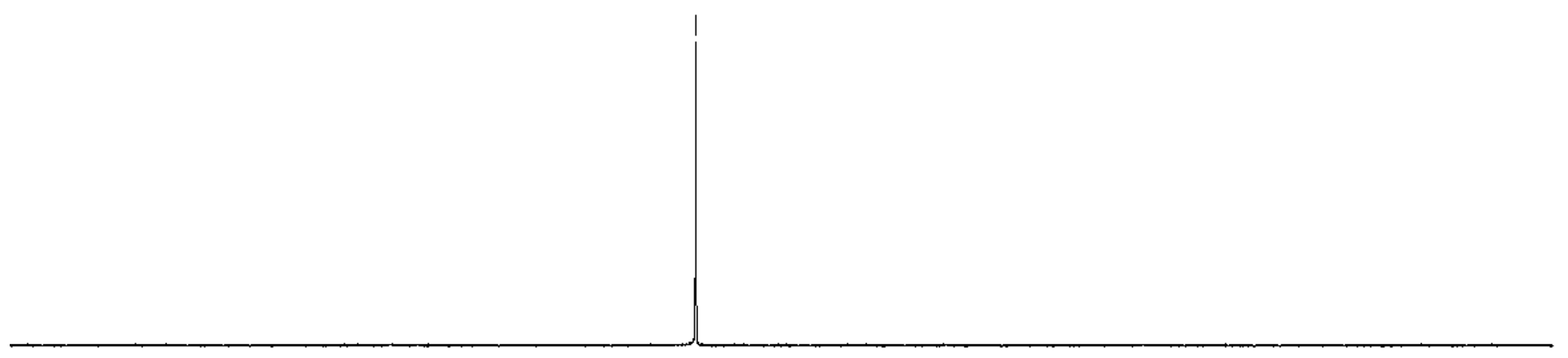



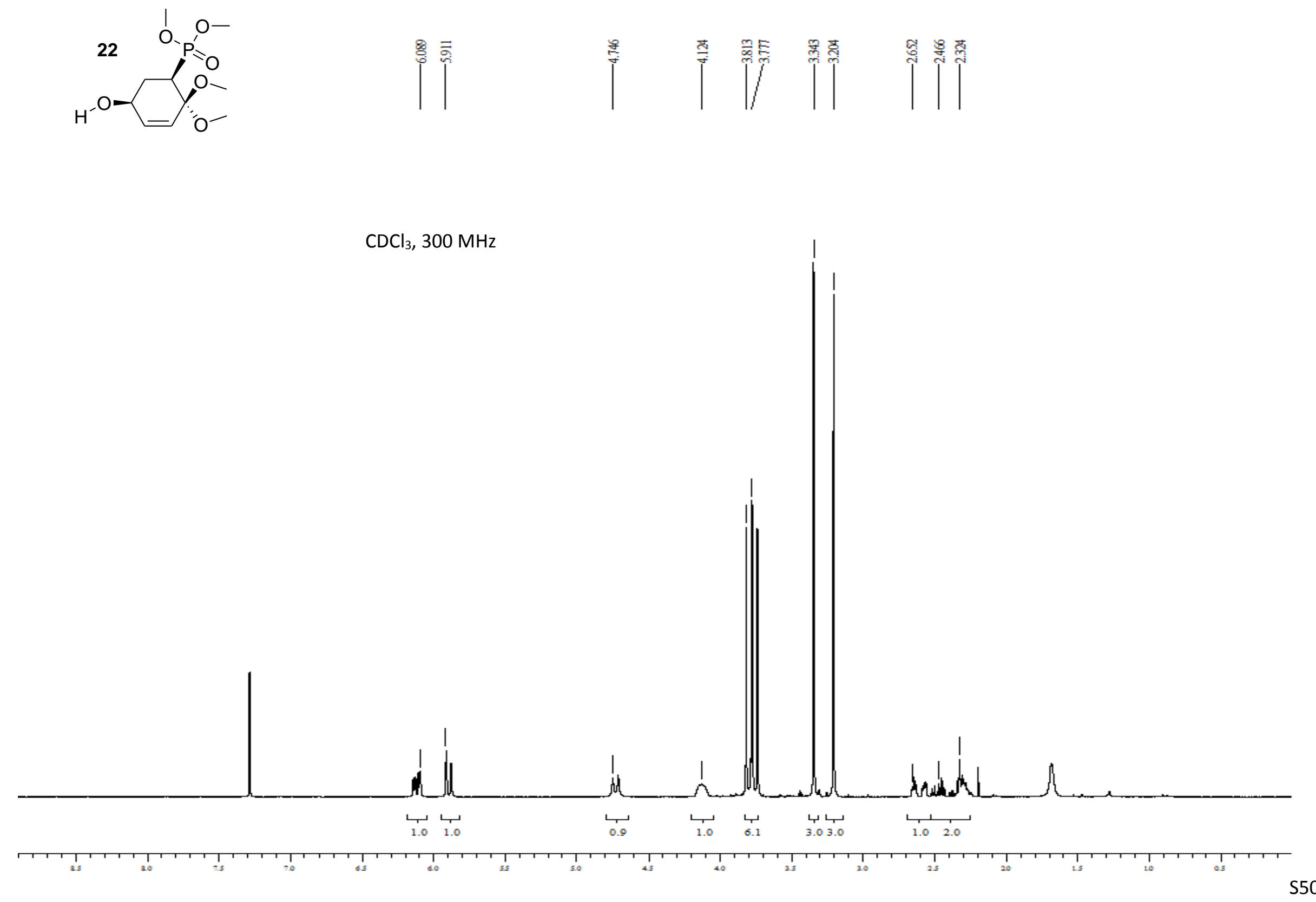

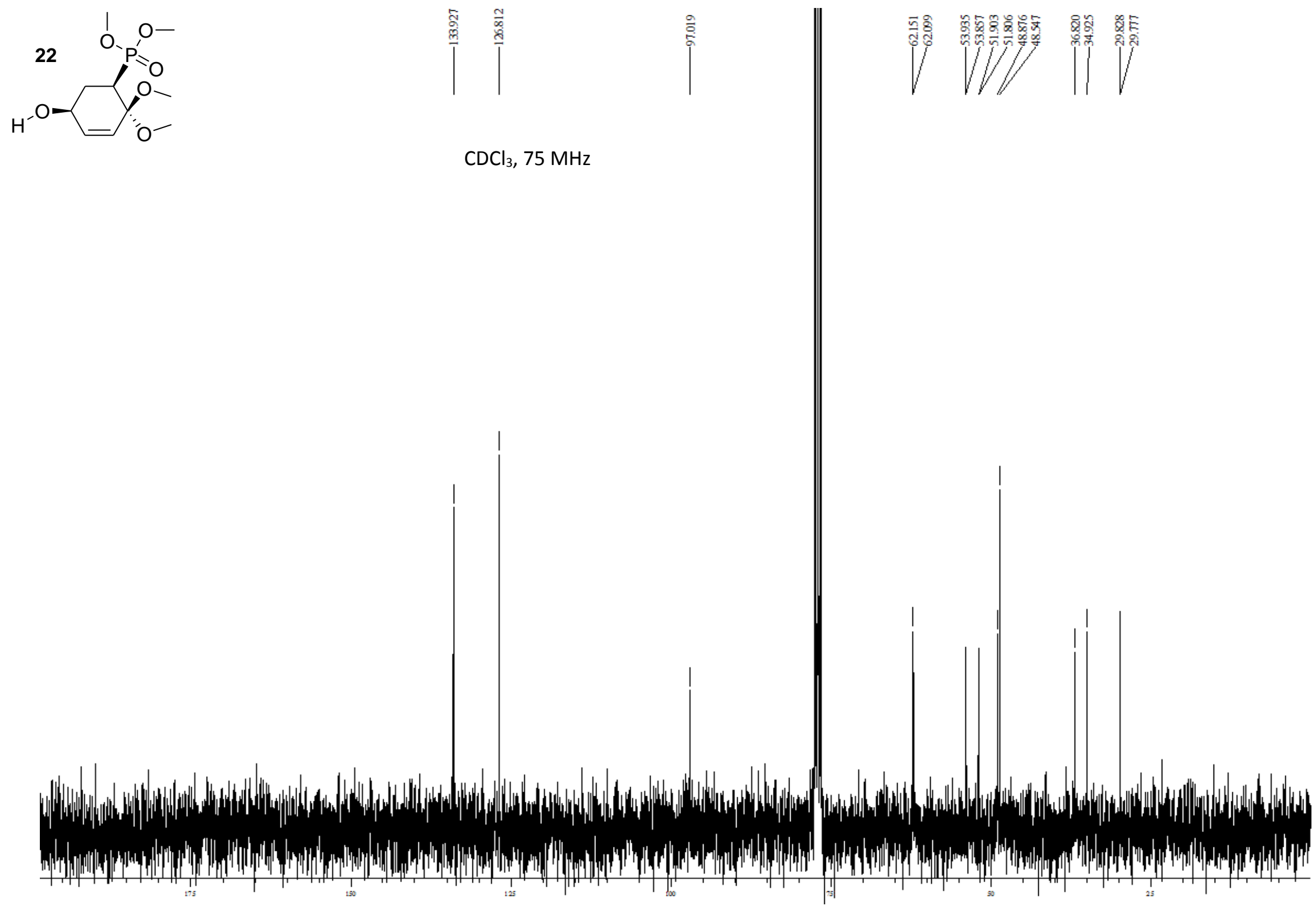


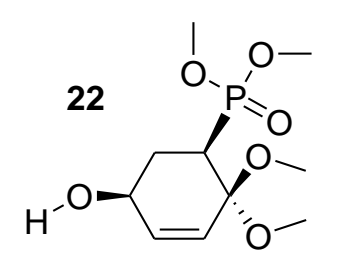

$\mathrm{CDCl}_{3}, 122 \mathrm{MHz}$

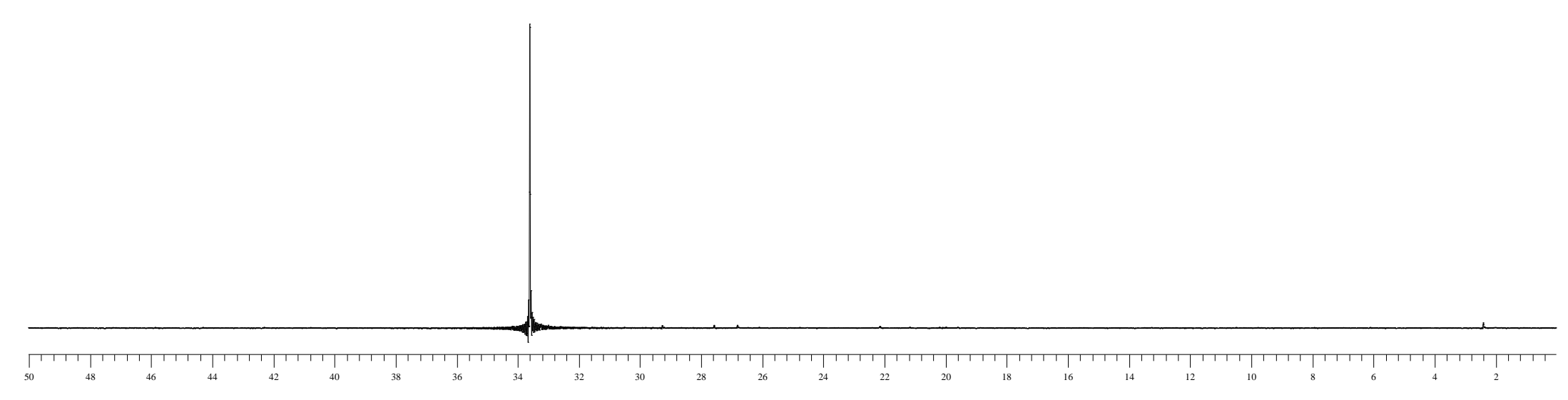




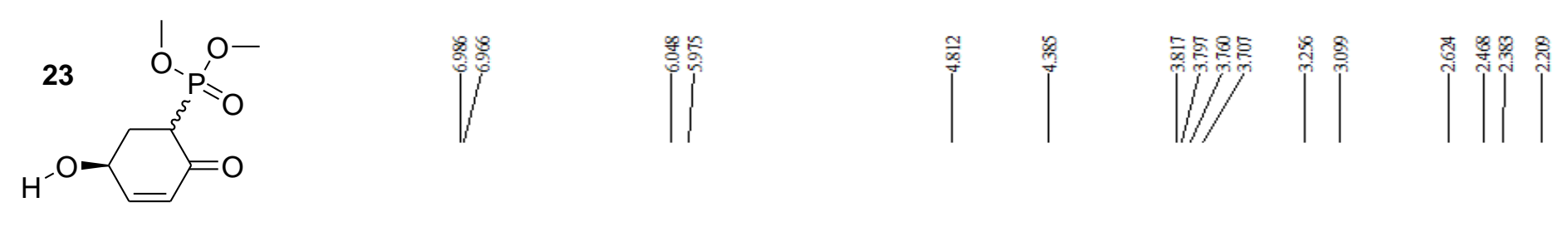

$\mathrm{CDCl}_{3}, 300 \mathrm{MHz}$

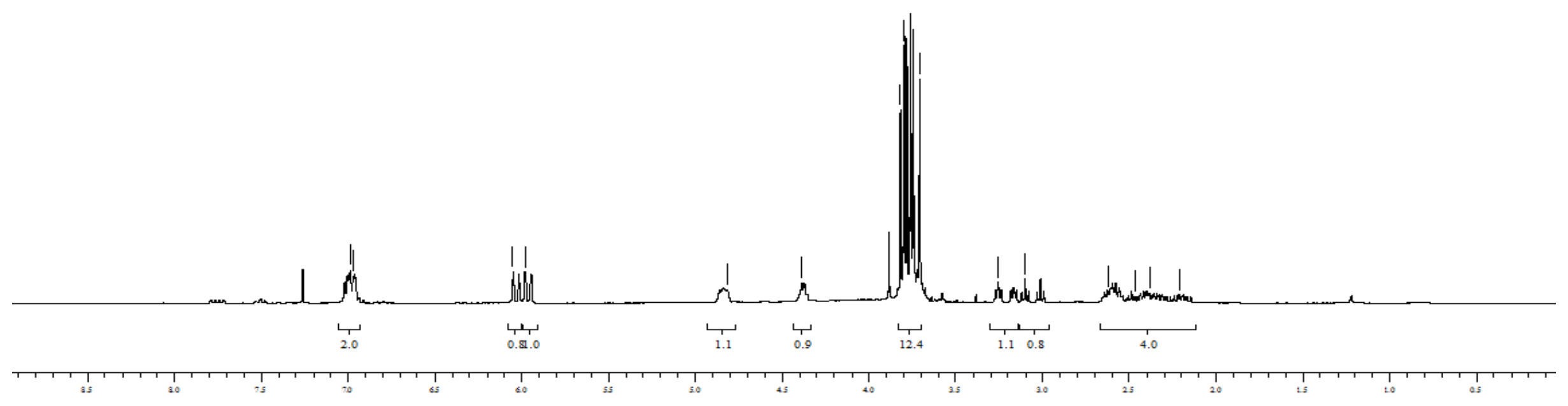




$$
\text { س }
$$



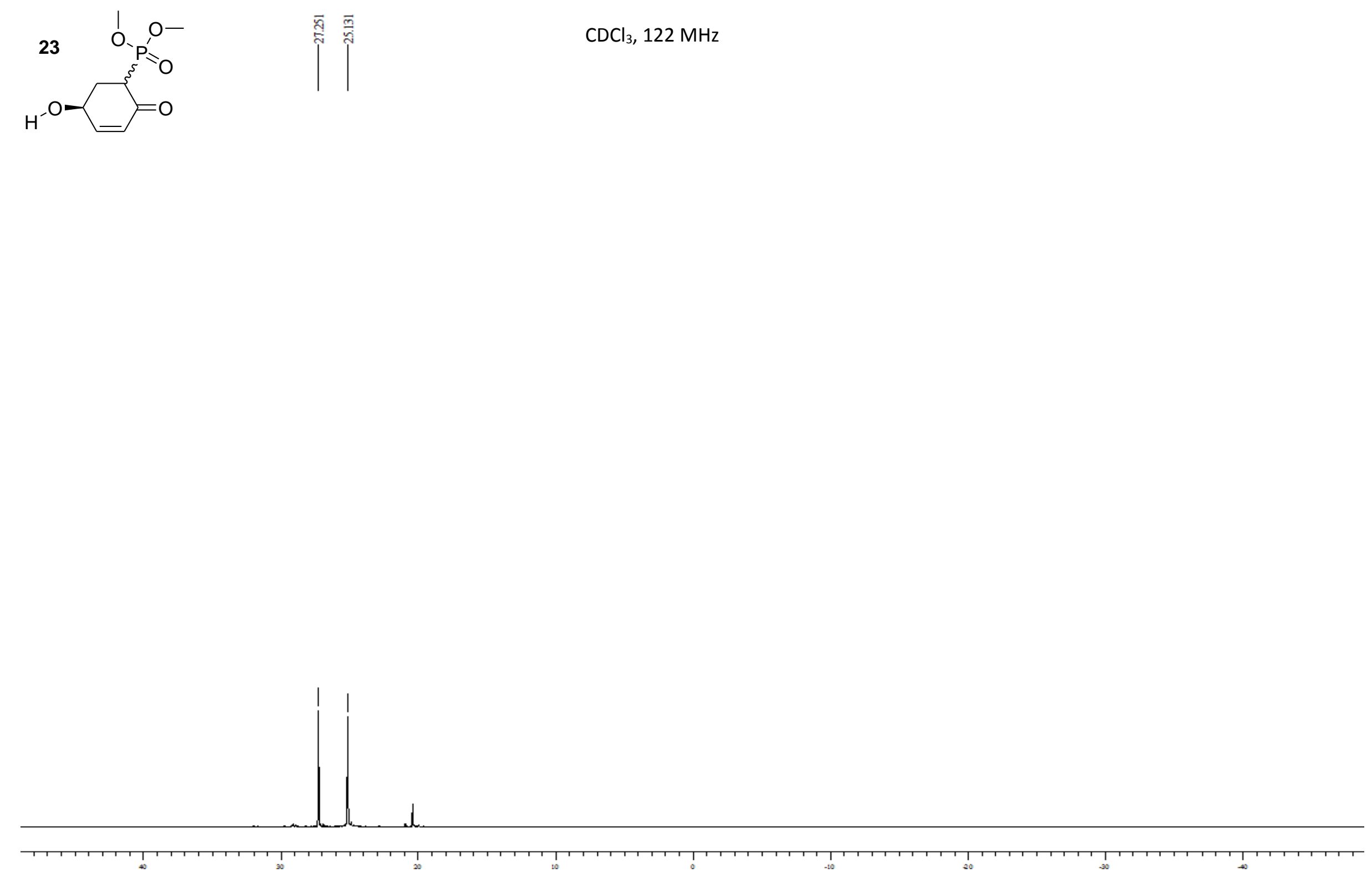

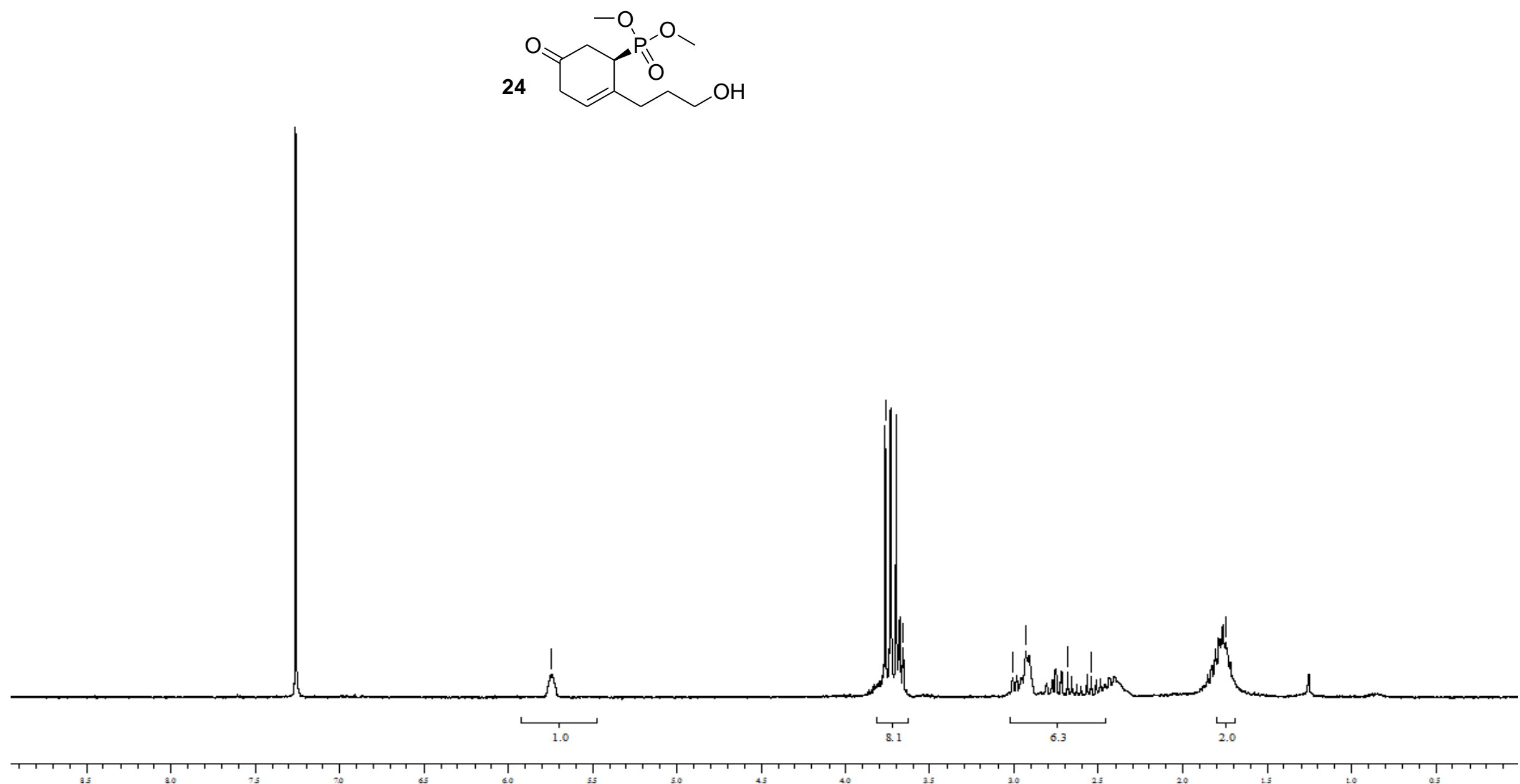

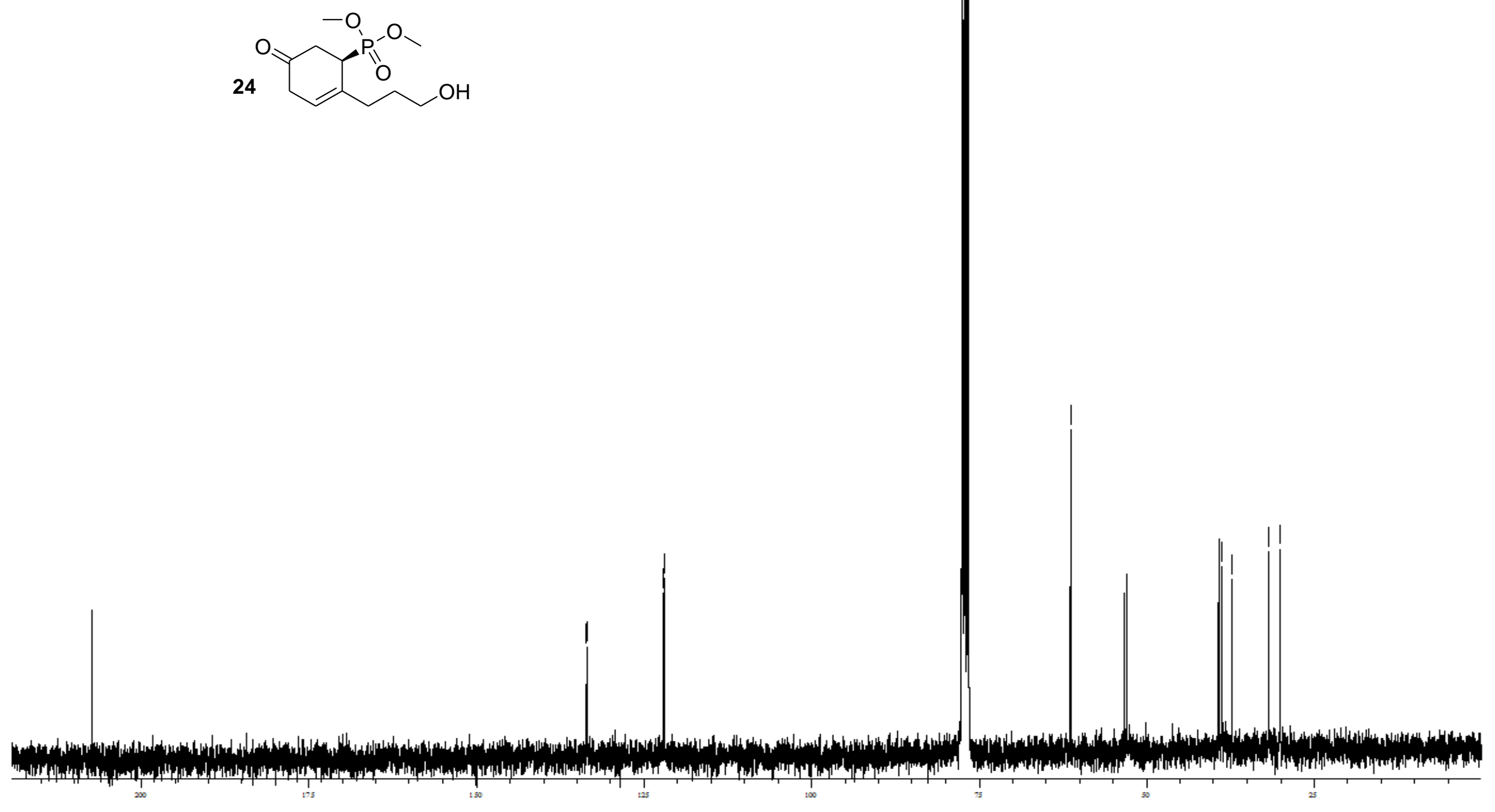


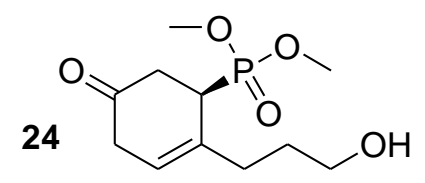

$\mathrm{CDCl}_{3}, 122 \mathrm{MHz}$

CDCl, $122 \mathrm{MH}$

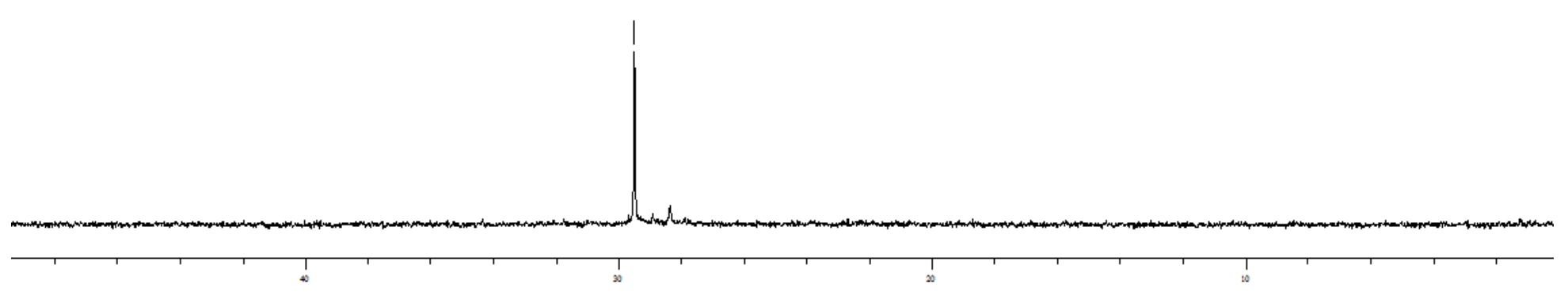



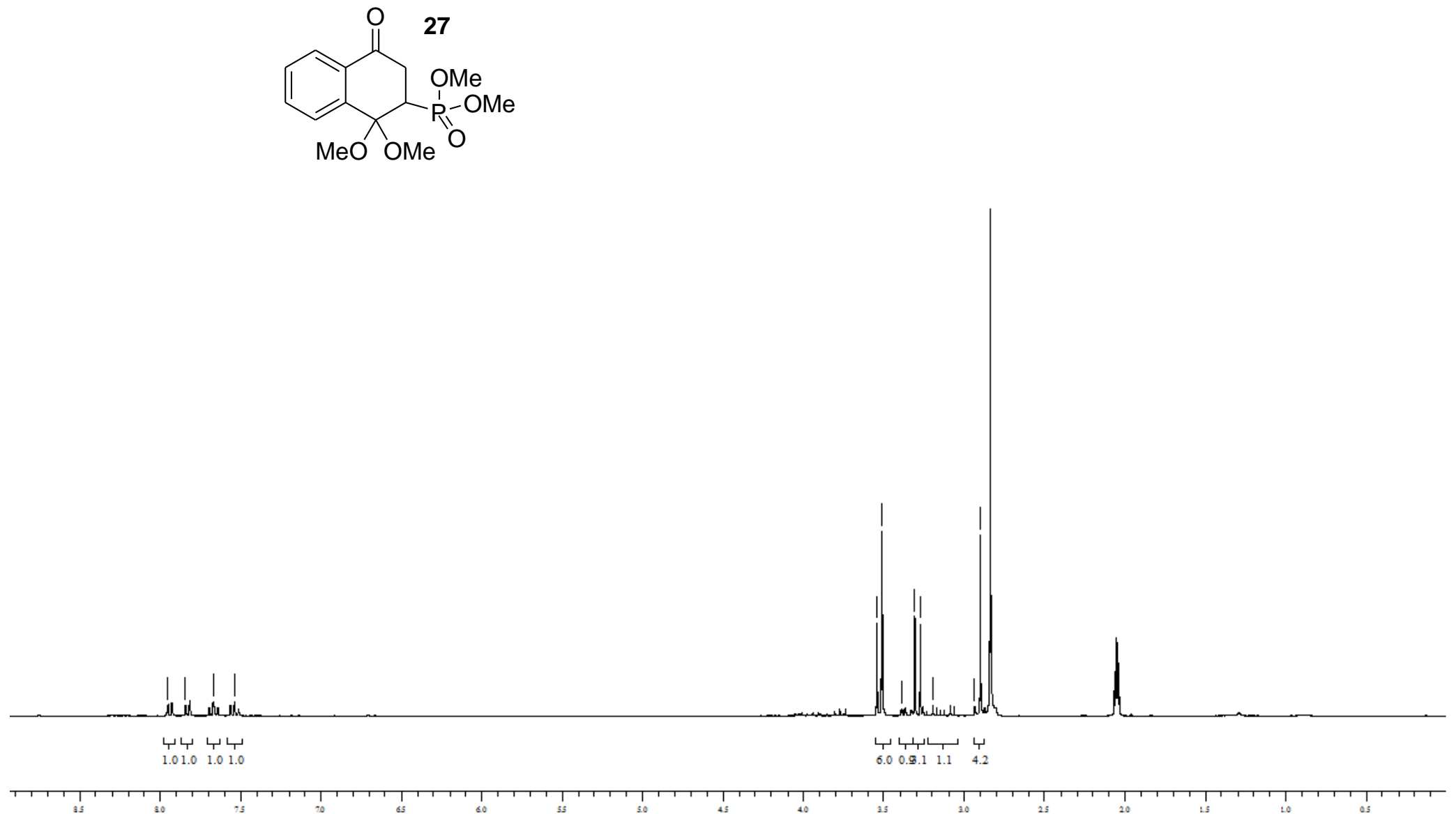


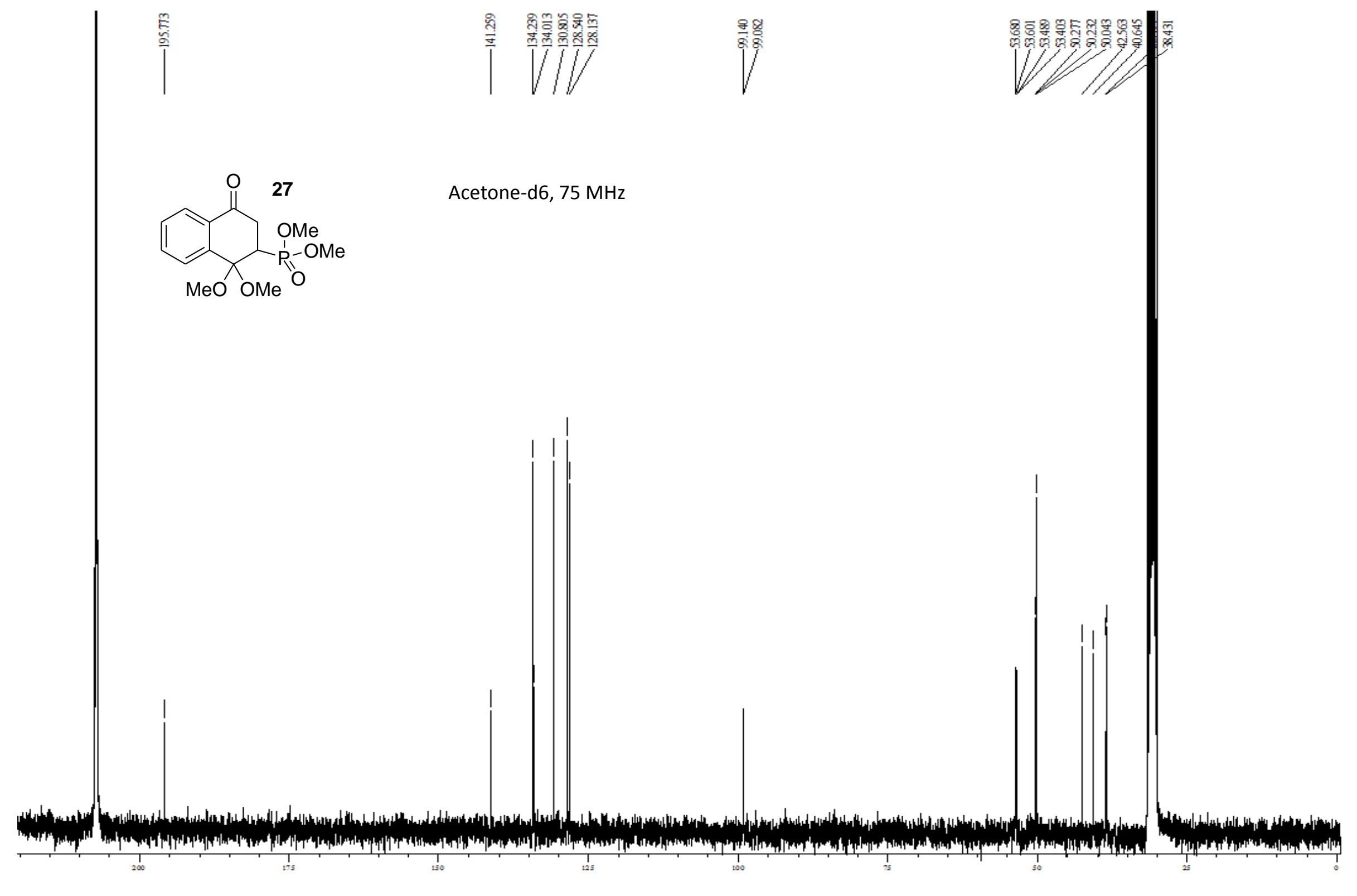




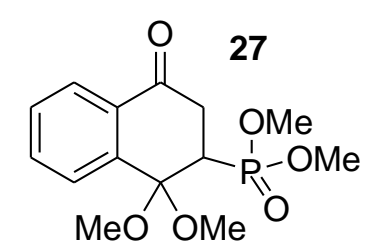

Acetone-d6, $122 \mathrm{MHz}$

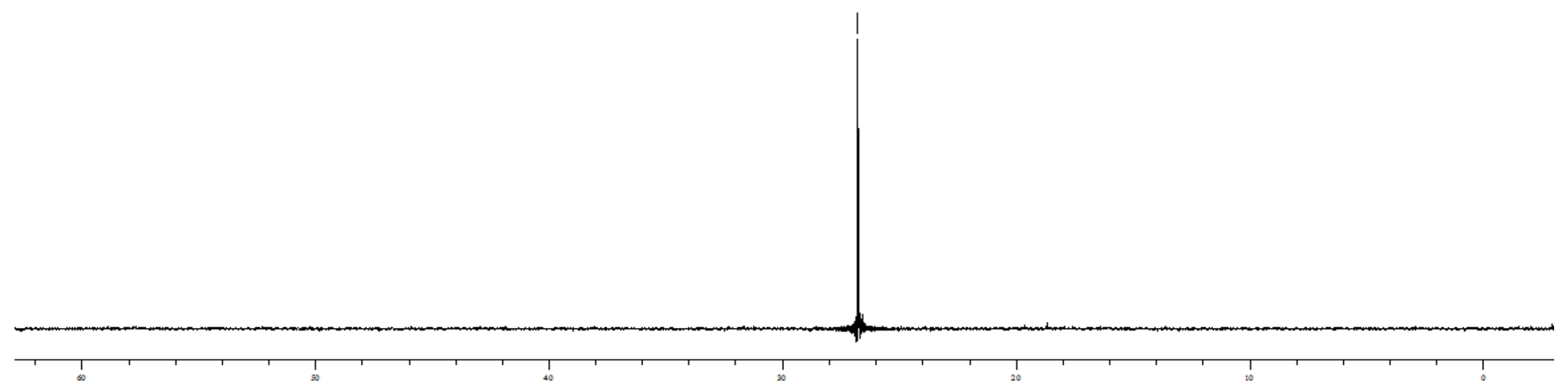

